\title{
Modeling mono- and multi-component adsorption of cobalt(II), copper(II), and nickel(II) metal ions from aqueous solution onto a new carboxylated sugarcane bagasse. Part I: Batch adsorption study
}

\author{
Stela Nhandeyara do Carmo Ramos ${ }^{\mathrm{a}}$, Amália Luísa Pedrosa Xavier ${ }^{\mathrm{a}}$, \\ Filipe Simões Teodoro ${ }^{a}$, Megg Madonyk Cota Elias ${ }^{a}$, Fernanda Jorge Gonçalves ${ }^{a}$, \\ Laurent Frédéric Gil ${ }^{\mathrm{a}}$, Rossimiriam Pereira de Freitas ${ }^{\mathrm{b}}$, Leandro Vinícius Alves Gurgel ${ }^{\mathrm{a}, *}$ \\ a Group of Physical Organic Chemistry (GPOC), Department of Chemistry, Institute of Biological and Exact Sciences (ICEB), Federal University of Ouro Preto, \\ Campus Morro do Cruzeiro, Bauxita, 35400-000 Ouro Preto, Minas Gerais, Brazil \\ b Department of Chemistry, Institute of Exact Sciences (ICEx), Federal University of Minas Gerais, Avenida Antônio Carlos, 6627, $31270-901$ Belo Horizonte, \\ Minas Gerais, Brazil
}

\section{A R T I C L E I N F O}

\section{Article history:}

Received 11 February 2015

Received in revised form 11 April 2015

Accepted 11 May 2015

Available online 10 June 2015

\section{Keywords:}

Sugarcane bagasse

Trimellitic anhydride

Adsorption

Metal ion

Desorption

\begin{abstract}
A B S T R A C T
A new carboxylated-functionalized sugarcane bagasse (STA) was prepared through the esterification of sugarcane bagasse with trimellitic anhydride. The optimized synthesis conditions yield STA with a percent weight gain of $73.9 \%$ and the number of carboxylic acid groups accounted for $3.78 \mathrm{mmol} / \mathrm{g}$. STA was characterized by FTIR, elemental analysis, TGA, PZC, and SEM. Adsorption kinetics followed a pseudosecond-order model. The adsorption rate constant showed the following order: $k_{2, \mathrm{Ni}}{ }^{2+}>k_{2, \mathrm{Cu}^{2+}}{ }^{2+k_{2, \mathrm{Co}}{ }^{2+}}$. Four mono- and multi-component isotherm models were used to model the adsorption systems. Monocomponent experimental data were fitted to Langmuir and Sips models; whereas, multicomponent data were fitted to modified extended Langmuir and $P$-factor models. The maximum adsorption capacities $\left(Q_{\text {max,mono }}\right)$ obtained from the Langmuir model were $1.140,1.197$, and $1.563 \mathrm{mmol} / \mathrm{g}$ for $\mathrm{Co}^{2+}$, $\mathrm{Cu}^{2+}$, and $\mathrm{Ni}^{2+}$, respectively. The competitive studies demonstrated that the multicomponent adsorption capacity

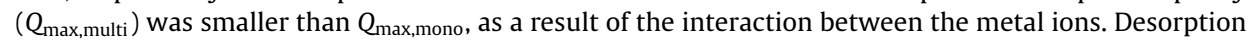
studies showed that all metal ions could be fully desorbed from STA.
\end{abstract}

(C) 2015 Elsevier B.V. All rights reserved.

\section{Introduction}

The Agency for Toxic Substances and Disease Registry (ATSDR, 2014) have classified some metals as toxic, persistent, and bioaccumulative elements. Among the most hazardous substances that impose risks to human health are various toxic metals (Ahmad and Prasad, 2011). Interestingly, arsenic (As), lead (Pb), and mercury $(\mathrm{Hg})$ are the top three most harmful metals, followed by cobalt (Co), nickel $(\mathrm{Ni})$, and copper $(\mathrm{Cu})$ at positions 51,57 , and 118 , respectively (Ahmad and Prasad, 2011; ATSDR, 2014). Such toxic metals are present in the ionic form in waste streams from mining operations, tanneries, batteries, electronics, electroplating, and petrochemicals as well as in textile and pesticide mills (Amin et al., 2013; Fu and Wang, 2011; Kazemipour et al., 2008). Toxic metals are some of the major pollutants in marine, soil, solid industrial wastes, and

\footnotetext{
* Corresponding author. Tel.: +55 313559 1707; fax: +55 3135591707.

E-mail addresses: legurgel@iceb.ufop.br, legurgel@yahoo.com.br (L.V.A. Gurgel).
}

untreated industrial wastewaters. Both solid and liquid industrial wastes can be considered as major sources of innumerous types of metals found in soil, groundwater, and water bodies (Amin et al., 2013; Kazemipour et al., 2008). The discharge of industrial effluents containing large amounts of toxic metals into the environment without suitable treatment has resulted in serious environmental problems (Amin et al., 2013; Barakat, 2011; Soetan et al., 2010).

$\mathrm{Co}, \mathrm{Cu}$, and $\mathrm{Ni}$ are all micronutrients for plants, animals, and humans (Ahmad and Prasad, 2011; Soetan et al., 2010). They participate in prosthetic groups and as co-factors of many enzymes and are, therefore, essential; however, at high concentrations, they can cause several serious health problems in humans (Ahmad and Prasad, 2011). The toxic effects of $\mathrm{Co}, \mathrm{Cu}$, and $\mathrm{Ni}$ are well documented (Klaassen, 2008).

Various physicochemical methods have been suggested for the removal of metal ions from industrial wastewaters such as electrochemical and chemical precipitation, ultrafiltration and nanofiltration, ion exchange, and reverse osmosis (Fu and Wang, 2011; Kazemipour et al., 2008). Such methods can be adopted 
alone or in combination, such as chemical precipitation followed by nanofiltration (Fu and Wang, 2011). Such processes have significant drawbacks, such as incomplete removal, high-energy requirements, and production of toxic sludge that needs to be treated and disposed (Barakat, 2011).

Recently, various studies have reported the development of cheaper and more effective technologies, aiming to decrease the amount of wastewater produced and enhance the standard quality of the treated effluent (Barakat, 2011; Fu and Wang, 2011). Adsorption has become one of the cheaper alternative treatments, as the search for low-cost adsorbents (modified or not) with a metal ion-binding capacity has been intensified (Bhatnagar and Sillanpää, 2010; Miretzky and Cirelli, 2010; Sun, 2010; Wan Ngah and Hanafiah, 2008). Agricultural by-products are promising candidates as effective adsorbents, owing to their low cost and availability throughout the world (Kumar, 2006). Among the most important low-cost agricultural by-products is sugarcane bagasse (SB). It is largely available in countries such as Brazil, China, and India, where it is a by-product from the sugar and bioethanol mills. Among these countries, Brazil is the world's largest producer of sugarcane (Ferreira et al., 2015). SB is mainly composed of cellulose $(42.19 \pm 1.93 \%)$, hemicelluloses $(27.60 \pm 0.88 \%)$, lignin $(21.56 \pm 1.67 \%)$, ash $(5.63 \pm 2.31 \%)$, and extractives $(2.84 \pm 1.22 \%)$ (Rocha et al., 2015). The three major components of SB are rich in primary and secondary hydroxyl groups that can be used to graft functional groups with a metal ion-binding capacity (Wan Ngah and Hanafiah, 2008).

This study aimed to prepare a new adsorbent with an improved metal ion-binding capacity from chemical modification of SB with trimellitic anhydride (TA). TA is a commercial and stable reagent. After esterification with SB, it releases two carboxylic acid groups that can form complexes with different metal ions. The chemical modification of SB was intensively studied and optimized. The new adsorbent material was used to study the removal of $\mathrm{Co}^{2+}, \mathrm{Cu}^{2+}$, and $\mathrm{Ni}^{2+}$ from spiked monocomponent and multicomponent aqueous solutions. The influence of time, $\mathrm{pH}$, and metal ion concentration on adsorption was studied in detail. Desorption and reuse of the spent adsorbent was also evaluated.

\section{Experimental}

\subsection{Materials}

$\mathrm{CoCl}_{2} \cdot 6 \mathrm{H}_{2} \mathrm{O}, \mathrm{CuSO}_{4} \cdot 5 \mathrm{H}_{2} \mathrm{O}, \mathrm{CH}_{3} \mathrm{COONa} \cdot 3 \mathrm{H}_{2} \mathrm{O}$, monochloroacetic acid (99\%), and isopropanol were purchased from Synth (Brazil). 1,2,4-Benzenetricarboxylic anhydride (trimellitic anhydride, TA) (97\%) (cat no. 552-30-7) and $3 \AA$ molecular sieve (cat no. 208582) were purchased from Sigma-Aldrich (Brazil). $\mathrm{NiCl}_{2} \cdot 6 \mathrm{H}_{2} \mathrm{O}$, glacial acetic acid (99.5\%), $\mathrm{NaOH}, \mathrm{HCl}(37 \% \mathrm{w} / \mathrm{w})$, acetone, $N, N^{\prime}-$ dimetylacetamide (DMA), and pyridine (Py) were purchased from Vetec (Brazil). Quantitative filter papers (blue ribbon, JP 41, cat no. $3509-1,12.5 \mathrm{~cm}$ diameter, ash content of $0.00009 \mathrm{~g}$, and grammage of $80 \mathrm{~g} / \mathrm{cm}^{2}$ ) were purchased from JProlab (Brazil). Before use, DMA was stored with molecular sieves ( $3 \AA$ ) that had been previously activated in an oven at $150^{\circ} \mathrm{C}$. Py was refluxed in a round-bottomed flask with $\mathrm{NaOH}$ pellets for $12 \mathrm{~h}$ and distilled before use.

\subsection{Sugarcane bagasse preparation}

SB stalks were provided by a local sugar and alcohol company, Ouro Preto, Minas Gerais, Brazil. The SB was dried under sunlight for 1 week, cut into $100 \mathrm{~mm}$ pieces, and milled in a wiley mill (DeLeo Brazil) to pass a 16-mesh screen. The SB was sifted on an electromagnetic stirrer (Bertel, Brazil) using a three-sieve system composed of $16(1.00 \mathrm{~mm}), 60(0.251 \mathrm{~mm})$, and $100(0.149 \mathrm{~mm})$ mesh for 10 min when set to vibrate with an amplitude of 1 . The fraction retained by the 60 -mesh screen was collected, transferred to a $5 \mathrm{~L}$ beaker, suspended, and stirred using a magnetic stirrer in distilled water at $70^{\circ} \mathrm{C}$ for $1 \mathrm{~h}$ to remove water-soluble compounds. The SB was then washed with distilled water, and acetone before being dried in an oven at $90^{\circ} \mathrm{C}$. To remove SB extractives, that is, phenolic compounds, it was washed in Soxhlet apparatus with hexane/ethanol $(1: 1, \mathrm{v} / \mathrm{v})$ for $4 \mathrm{~h}$, dried in an oven at $90^{\circ} \mathrm{C}$ to remove the organic solvents, and stored in a desiccator prior to use.

\subsection{Preparation of SB modified with trimellitic anhydride (STA)}

The chemical modification of SB with TA to obtain STA was optimized by studying the effect of reaction time and TA amount on the percent weight gain ( $p w g)$ and number of carboxylic acid groups $\left(n_{\mathrm{COOH}}\right)$.

\subsubsection{Modification of $S B$ as a function of the amount of TA}

SB (1.0 g), different amounts of TA $(2.0,4.0,6.0$ and 8.0 g), anhydrous DMA $(7.5 \mathrm{~mL})$, and anhydrous Py $(7.5 \mathrm{~mL})$ were added to a round-bottomed flask to give a solid-to-liquid ratio of $1: 15(\mathrm{w} / \mathrm{v})$ (SB:DMA/Py). Then, the flask was equipped with a reflux condenser attached to a drying tube packed with anhydrous calcium chloride. The suspensions were heated at $100^{\circ} \mathrm{C}$ in an oil bath under constant magnetic stirring (300 rpm) (Corning ${ }^{\circledR}$, model PC-420D) for $3 \mathrm{~h}$. At the end of each reaction, the suspensions were left to cool (30 min) and were then transferred to $250 \mathrm{~mL}$ beakers containing $125 \mathrm{~mL}$ of isopropanol. The suspensions were magnetically stirred for $30 \mathrm{~min}$ before being transferred to a sintered glass funnel $(150 \mathrm{~mL}$, porosity 3). This procedure was performed twice, using a total of $250 \mathrm{~mL}$ of isopropanol. Then, STAs were washed in a row with distilled water $(100 \mathrm{~mL}), 0.01 \mathrm{~mol} / \mathrm{L} \mathrm{HCl}$ solution $(100 \mathrm{~mL})$, distilled water $(100 \mathrm{~mL})$, and isopropanol $(50 \mathrm{~mL})$. The yellow solids (STAs) were dried in an oven at $95^{\circ} \mathrm{C}$ for $2.5 \mathrm{~h}$, put in a desiccator to cool, and weighed. The $p w g$ and $n_{\mathrm{COOH}}$ values were determined.

\subsubsection{Modification of $S B$ as a function of reaction time}

SB (1.0 g), TA ( $4.0 \mathrm{~g})$, anhydrous DMA $(7.5 \mathrm{~mL})$, and anhydrous Py $(7.5 \mathrm{~mL})$ were added to a round-bottomed flask to give a solidto-liquid ratio of $1: 15(\mathrm{w} / \mathrm{v})$. Then, the flask was equipped with a reflux condenser attached to a drying tube packed with anhydrous calcium chloride. The suspensions were heated at $100^{\circ} \mathrm{C}$ in an oil bath under constant magnetic stirring (300 rpm) (Corning ${ }^{\circledR}$, model PC-420D). Different reaction times were studied 1, 3, 6, 12, 18, 24, and $30 \mathrm{~h}$. The purification and characterization of STAs followed the same procedure described in Section 2.3.1.

\subsection{Characterization of STA}

\subsubsection{Percent weight gain ( $p w g)$}

The pwg after chemical modification of SB with TA was calculated using Eq. (1).

$p w g=\left(\frac{w_{\mathrm{STA}}-w_{\mathrm{SB}}}{w_{\mathrm{SB}}}\right) \times 100$

where $p w g(\%)$ is the percent weight gain, and $w_{\mathrm{STA}}$ and $w_{\mathrm{SB}}(\mathrm{g})$ are the weights of STA and SB after and before chemical modification, respectively.

\subsubsection{Number of carboxylic acid groups ( $\left.\mathrm{n}_{\mathrm{COOH}}\right)$}

The $n_{\mathrm{COOH}}$ of STA was determined by acid-base back titration. Two $0.1000 \mathrm{~g}$ samples of STA were weighed into $250 \mathrm{~mL}$ Erlenmeyer flasks and $100.0 \mathrm{~mL}$ of standardized $\mathrm{NaOH}$ solution $(10 \mathrm{mmol} / \mathrm{L})$ was added to each Erlenmeyer flask. The flasks were mechanically stirred at $25^{\circ} \mathrm{C}$ for $60 \mathrm{~min}$ at $100 \mathrm{rpm}$. The suspensions were filtered off using a single filtration (JP 41 filter paper). Three $20.0 \mathrm{~mL}$ 
aliquots from each Erlenmeyer flask were titrated with standardized $\mathrm{HCl}$ solution $(10 \mathrm{mmol} / \mathrm{L})$ until the phenolphthalein endpoint. The $n_{\mathrm{COOH}}$ of STA was calculated using Eq. (2).

$n_{\mathrm{COOH}}=\frac{\left[C_{\mathrm{NaOH}} V_{\mathrm{NaOH}}-f\left(C_{\mathrm{HCl}} V_{\mathrm{HCl}}\right)\right]}{w_{\mathrm{STA}}}$

where $n_{\mathrm{COOH}}(\mathrm{mmol} / \mathrm{g})$ is the number of carboxylic acid groups on STA, $C_{\mathrm{NaOH}}$ and $C_{\mathrm{HCl}}(\mathrm{mmol} / \mathrm{L})$ are the concentrations of standardized $\mathrm{NaOH}$ and $\mathrm{HCl}$ solutions, respectively, $V_{\mathrm{NaOH}}(\mathrm{L})$ is the volume of standardized $\mathrm{NaOH}$ solution, $V_{\mathrm{HCl}}(\mathrm{L})$ is the volume of standardized $\mathrm{HCl}$ solution expended titrating the excess of unreacted $\mathrm{NaOH}$, $w_{\text {STA }}(\mathrm{g})$ is the weight of SB modified with TA, and $f$ is a conversion factor $(f=5)$.

\subsubsection{Determination of the point of zero charge (PZC)}

To determine the PZC of STA, three different initial $\mathrm{pH}$ solutions $(3,6$, and 11$)$ were prepared using $0.1 \mathrm{~mol} / \mathrm{L} \mathrm{HNO}_{3}$ and $0.1 \mathrm{~mol} / \mathrm{L}$ $\mathrm{NaOH}$ solutions (Noh and Schwarz, 1990). For each initial $\mathrm{pH}$, $20.0 \mathrm{~mL}$ of $0.01 \mathrm{~mol} / \mathrm{L} \mathrm{NaNO}_{3}$ solution (background electrolyte) and different amounts of STA samples were added to five $125 \mathrm{~mL}$ Erlenmeyer flasks to give suspensions of $0.05,0.1,0.5,1$, and $2 \%(w / v)$. The flasks were mechanically stirred at $25^{\circ} \mathrm{C}$ for $24 \mathrm{~h}$ at $130 \mathrm{rpm}$ (Nova Ética, model 109/2). The equilibrium pH was measured using a $\mathrm{pH}$ meter (Hanna Instruments, model HI 223).

\subsubsection{Fourier transform infrared (FTIR) spectroscopy}

SB and STA were analyzed by FTIR spectroscopy. Samples were previously dried in an oven at $90^{\circ} \mathrm{C}$ for $1 \mathrm{~h}$. Then, $1.0 \mathrm{mg}$ of SB, STA, STA-loaded with $\mathrm{Co}^{2+}, \mathrm{Cu}^{2+}$, and $\mathrm{Ni}^{2+}$, and STA after desorption of $\mathrm{Co}^{2+}, \mathrm{Cu}^{2+}$, and $\mathrm{Ni}^{2+}$ were mixed with $100.0 \mathrm{mg}$ of spectroscopy grade $\mathrm{KBr}$ and pressed in a hydraulic press at 8 tons for $0.5 \mathrm{~min}$ to prepare $13 \mathrm{~mm} \mathrm{KBr}$ pellets (Pike CrushIR, model 181-1110, Pike Technologies, Canada). The FTIR spectra were recorded on an ABB Bomen MB 3000 FTIR spectrometer (Quebec, Canada) equipped with ZnSe optics and a DTGS detector at a resolution of $4 \mathrm{~cm}^{-1}$ from 500 to $4000 \mathrm{~cm}^{-1}$ with 32 scans per sample.

\subsubsection{Elemental analysis}

The carbon $(\mathrm{C})$, hydrogen $(\mathrm{H})$, and nitrogen $(\mathrm{N})$ contents in SB and STA were determined by elemental analysis. Samples were previously dried in an oven at $90^{\circ} \mathrm{C}$ for $1 \mathrm{~h}$. Elemental analysis was performed on a PerkinElmer Series II CHNS/O 2400 analyzer (Shelton, USA).

\subsubsection{Thermogravimetric analysis (TGA)}

TGA curves were recorded on a Shimadzu DTG-60H simultaneous TG-DTA thermogravimetric analyzer on an alumina pan under a nitrogen atmosphere at a flow rate of $100 \mathrm{~mL} / \mathrm{min}$ from 35 to $700^{\circ} \mathrm{C}$ at a linear heating rate of $10^{\circ} \mathrm{C} / \mathrm{min}$. Samples of SB and STA were previously dried in an oven at $90^{\circ} \mathrm{C}$ for $1 \mathrm{~h}$.

\subsubsection{Scanning electron microscopy (SEM)}

Morphologies of SB and STA were examined on a Vega3 SB scanning electron microscope (Tescan/Oxford Instruments) with a filament voltage of $20 \mathrm{keV}$ and secondary electron (SE) detector. Samples of SB and STA were previously dried in an oven at $90^{\circ} \mathrm{C}$ for $1 \mathrm{~h}$. Samples of SB and STA were placed on a graphite ribbon that was fixed on aluminum sample holders and sputter-coated with gold in a modular high-vacuum coating Q150R ES (Quorum Technologies).

\subsubsection{Energy dispersive X-ray (EDX) spectroscopy}

The surface of the STA adsorbent loaded with $\mathrm{Co}^{2+}, \mathrm{Cu}^{2+}$, and $\mathrm{Ni}^{2+}$ was mapped on a Vega3 SB SEM-EDX spectrometer (Tescan/Oxford Instruments) with a filament voltage of $20 \mathrm{keV}$ and backscattered electron (BSE) detector. Samples of STA loaded with metal ions were previously dried in an oven at $60^{\circ} \mathrm{C}$ for $12 \mathrm{~h}$. Samples of STA- $\mathrm{CO}^{2+}, \mathrm{Cu}^{2+}$, and $\mathrm{Ni}^{2+}(100 \mathrm{mg})$ were pressed in a hydraulic press at 8 tons for $1 \mathrm{~min}$ to prepare $13 \mathrm{~mm}$ pellets. The samples were sputter-coated with carbon in a modular highvacuum coating Q150R ES (Quorum Technologies).

\subsection{Adsorption experiments}

STA adsorbent was used for $\mathrm{Co}^{2+}, \mathrm{Cu}^{2+}$, and $\mathrm{Ni}^{2+}$ adsorption in aqueous mono- and multi-component solutions in batch mode. Adsorption was studied as a function of time (kinetics), pH, and initial metal ion concentration.

\subsubsection{Adsorption of metal ions on STA as a function of contact time (kinetics)}

Samples with $100.0 \mathrm{~mL}$ of $0.79 \mathrm{mmol} / \mathrm{L}$ metal ion solution buffered at $\mathrm{pH} 5.5$ for $\mathrm{Cu}^{2+}$ and 5.75 for $\mathrm{Co}^{2+}$ and $\mathrm{Ni}^{2+}$ using $0.05 \mathrm{~mol} / \mathrm{L} \mathrm{CH}_{3} \mathrm{COOH} / \mathrm{CH}_{3} \mathrm{COONa}$ were added to $250 \mathrm{~mL}$ Erlenmeyer flasks and pre-thermostated to $25^{\circ} \mathrm{C}$ in a shaker incubator for $1 \mathrm{~h}$ (Tecnal, model TE-424, Piracicaba, SP, Brazil). Then, $20.0 \mathrm{mg}$ samples of STA were weighed on cylindrical glasses (1.8 $\mathrm{mm}$ height and $2.2 \mathrm{~mm}$ diameter), added to each Erlenmeyer flask and stirred at $130 \mathrm{rpm}$ for different time intervals. After shaking, the solids were filtered off by a single filtration (JP 41 filter paper) and the metal ion concentration was determined by flame atomic absorption spectrophotometry (FAAS) $\left(\lambda_{\mathrm{Co}}=240.7 \mathrm{~nm}, \lambda_{\mathrm{Cu}}=324.8 \mathrm{~nm}\right.$, and $\lambda_{\mathrm{Ni}}=232 \mathrm{~nm}$ ). The amount of each metal ion adsorbed on STA in each time was calculated using Eq. (3).

$q_{t}=\frac{\left(C_{\mathrm{i}, \mathrm{M}^{2+}}-C_{\mathrm{t}, \mathrm{M}^{2+}}\right) V_{\mathrm{M}^{2+}}}{w_{\mathrm{STA}}}$

where $q_{t}(\mathrm{mmol} / \mathrm{g})$ is the amount of metal ion $\left(\mathrm{M}^{2+}\right)$ adsorbed per weight of STA at time $t, V_{\mathrm{M}}{ }^{2+}(\mathrm{L})$ is the volume of metal ion solution, $C_{\mathrm{i}, \mathrm{M}}{ }^{2+}$ and $C_{\mathrm{t}, \mathrm{M}}{ }^{2+}(\mathrm{mmol} / \mathrm{L})$ are the concentrations of metal ion solution at 0 and time $t$, and $w_{\text {STA }}(\mathrm{g})$ is the weight of STA adsorbent.

\subsubsection{Adsorption of metal ions on STA as a function of $\mathrm{pH}$}

STA samples $(20.0 \mathrm{mg}$ ) were weighed into $250 \mathrm{~mL}$ Erlenmeyer flasks and $100.0 \mathrm{~mL}$ of $0.79 \mathrm{mmol} / \mathrm{L}$ metal ion solution was added. Metal ion solutions were buffered at $\mathrm{pH}$ values from 2.0 to $3.5 \mathrm{using}$ $0.05 \mathrm{~mol} / \mathrm{L} \mathrm{ClCH}_{2} \mathrm{COOH} / \mathrm{ClCH}_{2} \mathrm{COONa}$ solutions and from 4.0 to 5.75 using $0.05 \mathrm{~mol} / \mathrm{L} \mathrm{CH}_{3} \mathrm{COOH} / \mathrm{CH}_{3} \mathrm{COONa}$ solutions. The Erlenmeyer flasks were transferred to a pre-thermostated shaker incubator at $25^{\circ} \mathrm{C}$ and mechanically stirred at $130 \mathrm{rpm}$ until equilibrium was reached. After shaking, the solids were filtered off by a single filtration (JP 41 filter paper) and the metal ion concentration was determined by FAAS. The solubility product constant $\left(K_{\mathrm{sp}}\right)$ for $\mathrm{Co}(\mathrm{OH})_{2}\left(5.92 \times 10^{-15}\right), \mathrm{Cu}(\mathrm{OH})_{2}\left(1.8 \times 10^{-20}\right)$, and $\mathrm{Ni}(\mathrm{OH})_{2}$ $\left(5.48 \times 10^{-16}\right)$ were used to calculate the maximum $\mathrm{pH}$ value of the metal ion solutions to avoid the formation of hydrolyzed species and precipitation (Haynes, 2014).

\subsubsection{Adsorption isotherms}

2.5.3.1. Monocomponent.

STA samples $(20.0 \mathrm{mg}$ ) were weighed into $250 \mathrm{~mL}$ Erlenmeyer flasks and $100.0 \mathrm{~mL}$ of each metal ion solution (buffered at pH 5.5 for $\mathrm{Cu}^{2+}$ and 5.75 for $\mathrm{Co}^{2+}$ and $\mathrm{Ni}^{2+}$ with $0.05 \mathrm{~mol} / \mathrm{L}$ $\mathrm{CH}_{3} \mathrm{COOH} / \mathrm{CH}_{3} \mathrm{COONa}$ solution), with concentrations ranging from 0.05 to $1.12 \mathrm{mmol} / \mathrm{L}$, were added. Further procedures were the same described in Sections 2.5.1 and 2.5.2.

\subsubsection{Multicomponent.}

STA samples $(20.0 \mathrm{mg}$ ) were weighed into $250 \mathrm{~mL}$ Erlenmeyer flasks and $100.0 \mathrm{~mL}$ of binary equimolar metal ion solutions 


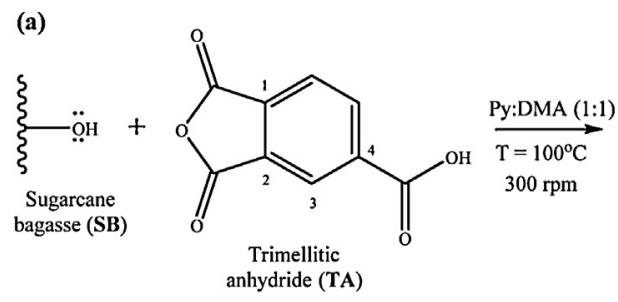<smiles>CCOC(=O)c1ccc(C(=O)O)cc1C(=O)O</smiles>

(b)

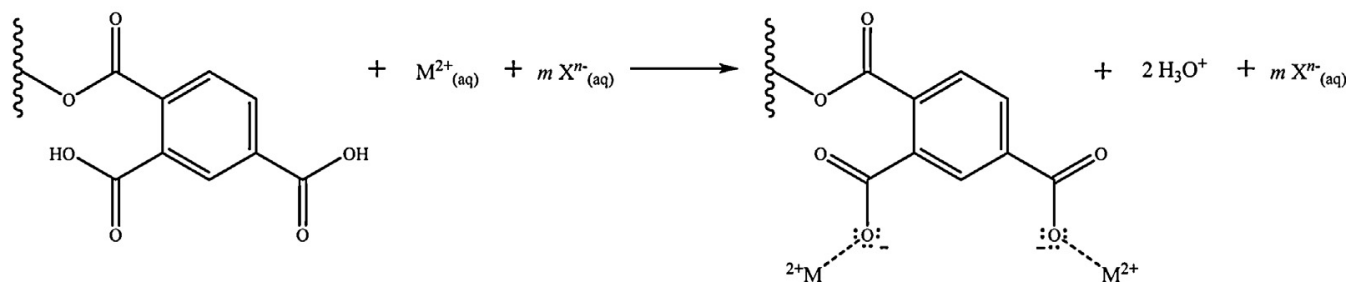

Fig. 1. (a) Scheme illustrating the synthesis strategy used to prepare STA and (b) suggested mechanism of adsorption of metal ions $\left(\mathrm{M}^{2+}\right)$ on STA adsorbent $(M=\mathrm{Co}$, $\mathrm{Cu}$, or $\mathrm{Ni}$ and $\mathrm{mX}^{n-}=$ counter ion $\left(\mathrm{SO}_{4}^{2-}\right.$ or $\left.\mathrm{Cl}^{-}\right)$).

Table 1

The results of optimizing the chemical modification of SB with TA.

\begin{tabular}{|c|c|c|c|}
\hline \multirow[t]{2}{*}{ Trimellitic anhydride (TA) (g) } & \multirow[t]{2}{*}{ Reaction time (h) } & \multicolumn{2}{|l|}{$\mathrm{STA}^{\mathrm{a}}$} \\
\hline & & $p w g(\%)$ & $n_{\mathrm{COOH}}(\mathrm{mmol} / \mathrm{g})$ \\
\hline 1.0 & 3 & $16.79 \pm 1.42$ & $1.91 \pm 0.01$ \\
\hline 2.0 & & $42.91 \pm 2.40$ & $2.97 \pm 0.02$ \\
\hline 6.0 & & $64.93 \pm 1.26$ & $3.74 \pm 0.16$ \\
\hline \multirow[t]{5}{*}{4.0} & 1 & $47.61 \pm 0.93$ & $3.10 \pm 0.08$ \\
\hline & 3 & $60.72 \pm 3.11$ & $3.75 \pm 0.01$ \\
\hline & 18 & $77.55 \pm 3.35$ & $4.78 \pm 0.19$ \\
\hline & 24 & $88.55 \pm 0.89$ & $4.72 \pm 0.03$ \\
\hline & 30 & $64.69 \pm 1.63$ & $4.49 \pm 0.13$ \\
\hline
\end{tabular}

a The weight of SB used in all chemical modifications was $1.0 \mathrm{~g}$. All reactions were performed in duplicate.

(buffered at pH 5.5 with $0.05 \mathrm{~mol} / \mathrm{L} \mathrm{CH}_{3} \mathrm{COOH} / \mathrm{CH}_{3} \mathrm{COONa}$ solution), with concentrations ranging from 0.05 to $1.12 \mathrm{mmol} / \mathrm{L}$ for $\mathrm{Co}^{2+}-\mathrm{Ni}^{2+}, \mathrm{Cu}^{2+}-\mathrm{Ni}^{2+}$, and $\mathrm{Co}^{2+}-\mathrm{Cu}^{2+}$, were added. Further procedures were the same described in Sections 2.5.1 and 2.5.2.

\subsection{Desorption experiments}

STA samples $(100.0 \mathrm{mg}$ ) were loaded with $100.0 \mathrm{~mL}$ of buffered metal ion solution $\left(3.15 \mathrm{mmol} / \mathrm{L}\right.$ for $\mathrm{Co}^{2+}, \mathrm{Cu}^{2+}$, and $\left.\mathrm{Ni}^{2+}\right)$ at $\mathrm{pH}$ $5.5\left(0.05 \mathrm{~mol} / \mathrm{L} \mathrm{CH}_{3} \mathrm{COOH} / \mathrm{CH}_{3} \mathrm{COONa}\right.$ solution) for 180,250 , and $75 \mathrm{~min}$, that is, the optimal parameters determined from adsorption studies for $\mathrm{Co}^{2+}, \mathrm{Cu}^{2+}$, and $\mathrm{Ni}^{2+}$, respectively. Samples of STA-loaded with each metal ion were recovered by a single filtration, washed with an excess of deionized water (Millipore, model Milli- $\mathrm{Q}^{\mathrm{TM}}$ Simplicity ${ }^{\mathrm{TM}}$ ) to remove metal ions that were not adsorbed on STA, dried in an oven at $60^{\circ} \mathrm{C}$ for $12 \mathrm{~h}$, and weighed. Dried samples of STA $(20.0 \mathrm{mg})$ loaded with each metal ion were weighed into $250 \mathrm{~mL}$ Erlenmeyer flasks and $20.0 \mathrm{~mL}$ of aqueous desorption solution ( $\left.1.0 \mathrm{~mol} / \mathrm{L} \mathrm{HNO}_{3}\right)$ was added. The Erlenmeyer flasks were transferred to a pre-thermostated shaker incubator at $25^{\circ} \mathrm{C}$ and mechanically stirred at $130 \mathrm{rpm}$ for $5 \mathrm{~min}$. Further procedures were the same described in Sections 2.5.1 and 2.5.2. The desorption efficiency $\left(E_{\mathrm{des}}\right)$ of each STA-metal ion system was calculated using Eq. (4).

$E_{\mathrm{des}}=\left(\frac{C_{\mathrm{e}, \mathrm{M}^{2+}} V}{Q_{\mathrm{T}, \mathrm{max}} w_{\mathrm{STA}}}\right) \times 100$ where $E_{\mathrm{des}}(\%)$ is the desorption efficiency, $C_{\mathrm{e}, \mathrm{M}^{2+}}(\mathrm{mmol} / \mathrm{L})$ is the equilibrium concentration of $\mathrm{M}^{2+}$ in aqueous desorption solution, $V(\mathrm{~L})$ is the volume of desorption solution, $Q_{\mathrm{T}, \max }(\mathrm{mmol} / \mathrm{g})$ is the theoretical maximum adsorption capacity calculated for each metal ion, and $w_{\text {STA }}(\mathrm{g})$ is the weight of STA-loaded with each metal ion.

\subsubsection{Reuse of the spent adsorbent after desorption}

Samples of $20.0 \mathrm{mg}$ of STA (dried in an oven at $80^{\circ} \mathrm{C}$ for $1 \mathrm{~h}$ ) from the desorption study were weighed into $250 \mathrm{~mL}$ Erlenmeyer flasks and $100.0 \mathrm{~mL}$ of $0.79 \mathrm{mmol} / \mathrm{L}$ metal ion solution was added. The optimal parameters determined from adsorption studies were used. Further procedures were the same as those described in Sections 2.5.1 and 2.5.2. The re-adsorption efficiency $\left(E_{\text {re-ads }}\right)$ of STA for a cycle of adsorption of metal ion after desorption was calculated using Eq. (5).

$\begin{aligned} E_{\mathrm{re}-\mathrm{ads}}= & \frac{\left\{\left[\left(w_{\mathrm{STA}, \mathrm{M}^{2+}}-w_{\mathrm{STA}}\right) Q_{\mathrm{T}, \max }\right]_{\mathrm{des}}+\left(Q_{\max } w_{\mathrm{STA}}\right)_{\mathrm{ads}}\right\} / w_{\mathrm{STA}}}{Q_{\mathrm{T}, \max }} \\ & \times 100\end{aligned}$

where $E_{\text {re-ads }}(\%)$ is the re-adsorption efficiency, $w_{\mathrm{STA}, \mathrm{M}}{ }^{2+}(\mathrm{g})$ is the weight of STA-loaded with metal ions, $w_{\text {STA }}(\mathrm{g})$ (inside brackets with subscript des) is the weight of STA after desorption (determined from $w_{\mathrm{STA}, \mathrm{M}}{ }^{2+}$ and the desorption efficiency, $\left.E_{\mathrm{des}}\right), Q_{\max }$ $(\mathrm{mmol} / \mathrm{g})$ is the new maximum adsorption capacity obtained from re-adsorption study, and $w_{\text {STA }}(\mathrm{g})$ is the weight of STA used in the re-adsorption study. The subscripts des and ads in Eq. (5) are related to the desorption and re-adsorption experiments. 


\section{Results and discussions}

\subsection{Synthesis and characterization of STA}

\subsubsection{Percent weight gain (pwg) and number of carboxylic acid groups $\left(n_{\mathrm{COOH}}\right)$}

Fig. 1 shows the synthetic strategy used to prepare the STA adsorbent and a suggested adsorption mechanism for metal ions $\left(\mathrm{M}^{2+}\right)$ on STA. The modification of SB with TA using Py as the base/catalyst and DMA as the solvent to obtain STA was optimized by studying the effects of reaction time and TA amount on the $p w g$ and $n_{\mathrm{COOH}}$ values. The results of the reaction optimization are shown in Table 1, which shows that, as the amount of TA was increased, $p w g$ and $n_{\mathrm{COOH}}$ also increased. The increase in the amount of TA from 4.0 to $6.0 \mathrm{~g}$ yielded a small increase in the $p w g$, but the value of $n_{\mathrm{COOH}}$ was almost the same, considering the standard deviation. Thus, $4.0 \mathrm{~g}$ of TA was chosen as the best amount to obtain the highest $n_{\mathrm{COOH}}$ for the subsequent experiments as a function of reaction time. As the reaction time increased, $p w g$ and $n_{\mathrm{COOH}}$ also increased until $24 \mathrm{~h}$. After $24 \mathrm{~h}$, both $p w g$ and $n_{\mathrm{COOH}}$ decreased, which is probably because of the chemical degradation of STA caused by the longer heating time. A longer heating time may also allow diesterification reactions, which could diminish the weight gain caused by the release of water molecules. Water molecules can also hydrolyze the ester bonds between hydroxyl groups of SB and the trimellitate moiety, allowing a decreasing in both $p w g$ and $n_{\mathrm{COOH}}$. Furthermore, longer reaction times can substantially increase the preparation cost of STA. Therefore, taking into account the obtained results, a reaction time of $6 \mathrm{~h}$ and a TAto-SB ratio of $4: 1$ were chosen to prepare a larger amount of STA in order to accomplish the adsorption experiments. When increasing the scale of the reaction to $10.0 \mathrm{~g}$ of $\mathrm{SB}$ and $40.0 \mathrm{~g}$ of TA, pwg and $n_{\mathrm{COOH}}$ became $73.9 \%$ and $3.78 \pm 0.03 \mathrm{mmol} / \mathrm{g}$, respectively. The scale-up of the reaction resulted in a pwg increase of $15.5 \%$ and a $n_{\mathrm{COOH}}$ decrease of $11.1 \%$. The estimated preparation cost of STA (TA/SB ratio of $4: 1$ and reaction time of $6 \mathrm{~h}$ ), considering the international market prices of the chemicals used, $\mathrm{SB}$, and electricity in Brazil, was US $\backslash \$ 57.43$ per kilogram of STA. This preparation cost did not include the elaboration steps described in Section 2.3.1.

\subsubsection{Elemental analysis and FTIR spectroscopy}

Elemental and FTIR spectroscopy analyses were performed for unmodified SB and TA-modified SB. The carbon, hydrogen, nitrogen, and oxygen contents for SB and STA were 46.56 and $52.45 \%$, 5.09 and $4.10 \%, 0.30$ and $0.97 \%$, and 48.06 and $42.49 \%$, respectively. The oxygen content was indirectly obtained by calculating the difference. Fig. 2a shows the FTIR spectra for SB and STA. The main changes highlighted in the FTIR spectrum for SB in comparison with STA are: (1) the appearance of a band at $2640 \mathrm{~cm}^{-1}$, which can be attributed to the stretching of hydrogen bonding present in the dimmer of carboxylic acid; (2) a strong band at $1717 \mathrm{~cm}^{-1}$, which can be attributed to the stretching of conjugated carbonyl ester; (3) a band at $1491 \mathrm{~cm}^{-1}$, which can be attributed to the stretching of $\mathrm{C}=\mathrm{C}$ bonds in the aromatic ring of the trimellitate moiety; (4) a band at $1281 \mathrm{~cm}^{-1}$, which can be attributed to the $\mathrm{C}-\mathrm{O}$ stretching of esters of aromatic acids; and (5) a band at $754 \mathrm{~cm}^{-1}$, which can be attributed to $\mathrm{C}-\mathrm{H}$ out-of-plane bending for the 1,2,4-substituted benzenoid compound (Pavia et al., 2009). These changes confirmed the introduction of the trimellitate group to the SB. Similar band assignments were reported by Saikia et al. (1993), who esterified different cellulose pulps with TA.

Fig. 2b shows FTIR spectra for STA and STA-loaded with $\mathrm{Co}^{2+}$, $\mathrm{Cu}^{2+}$, and $\mathrm{Ni}^{2+}$. The adsorption of metal ions on STA was characterized by the two new bands arising at 1592 and $1552 \mathrm{~cm}^{-1}$, which can be attributed to asymmetric stretching of different carboxylate groups and indicate the complete deprotonation of carboxylic acid
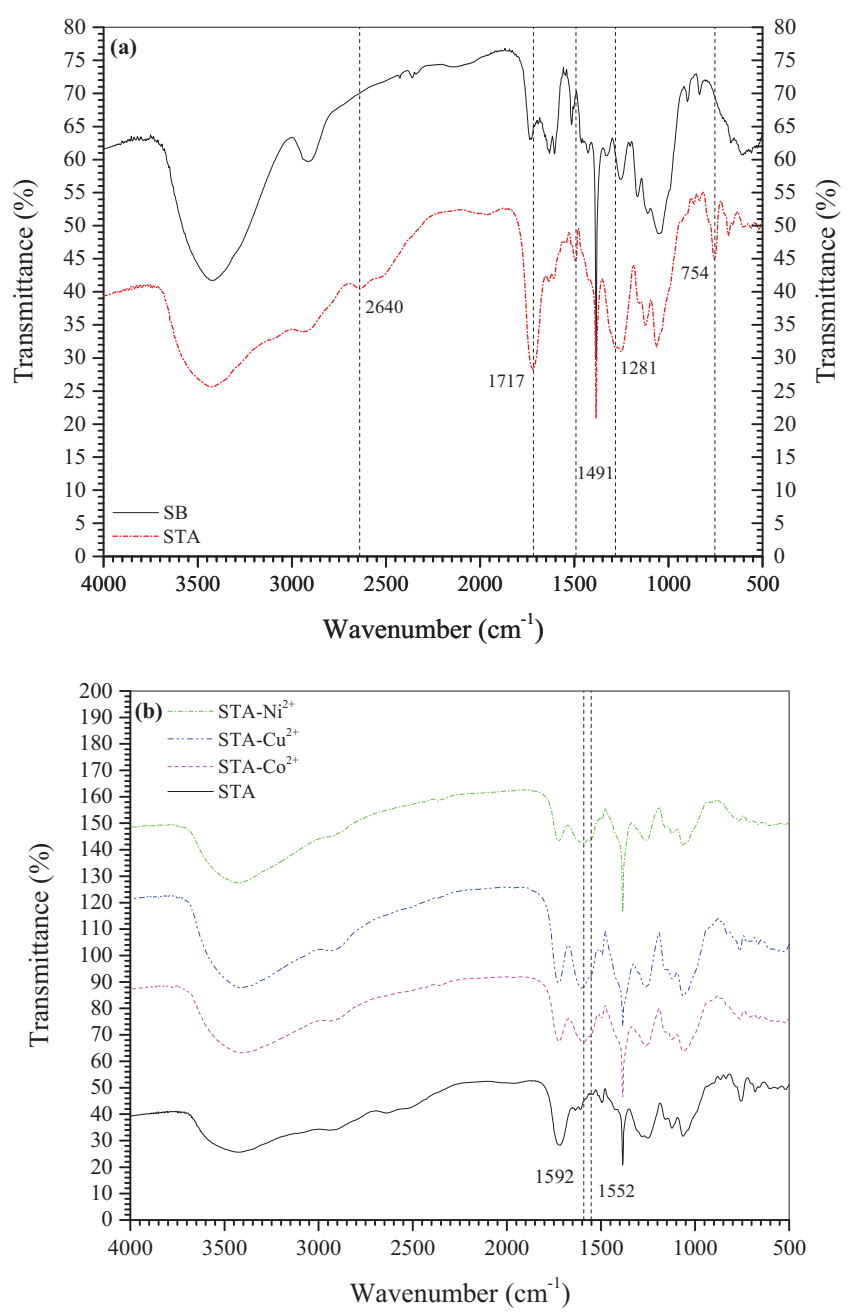

Fig. 2. FTIR spectra of (a) SB and STA and (b) STA and STA-loaded with $\mathrm{Co}^{2+}, \mathrm{Cu}^{2+}$, and $\mathrm{Ni}^{2+}$ (transmittances of STA- $\mathrm{Co}^{2+}, \mathrm{STA}-\mathrm{Cu}^{2+}$, and STA- $\mathrm{Ni}^{2+}$ spectra were shifted by 30,60 and $90 \%)$.

groups during the adsorption process. These bands prove the participation of all carboxylate groups during the adsorption of metal ions, as suggested in the adsorption mechanism proposed in Fig. 1b (Łyszczek, 2007). According to Łyszczek (2007), the splitting of the carboxylate band is suggestive of the presence of a non-equivalence of carboxylate groups. The similarities between the spectra of STAloaded with $\mathrm{Co}^{2+}, \mathrm{Cu}^{2+}$, and $\mathrm{Ni}^{2+}$ suggest similar metal coordination through the carboxylate groups.

\subsubsection{Thermogravimetric analysis (TGA)}

TGA data for the thermal decomposition of SB and STA are presented in Table 2. TGA and DTG curves are shown in Supplementary Fig. 1. As can be seen in Supplementary Fig. 1 and Table 2, the first weight loss occurred at $T_{\mathrm{m}, 1}=53-58^{\circ} \mathrm{C}$ for SB and STA, which can be attributed to the vaporization of bound water. The TGA curve of SB exhibited two main decomposition events. The DTG peaks at $T_{\mathrm{m}, 2}=322^{\circ} \mathrm{C}$ and $T_{\mathrm{m}, 3}=368.5^{\circ} \mathrm{C}$ for SB are attributed to hemicelluloses and cellulose decomposition, which break down faster than lignin, yielding volatile compounds (Varhegyi et al., 1989). The thermal decomposition of lignin follows a slow charring process over a broad temperature range above $400^{\circ} \mathrm{C}$ (flat DTG portion) and does not exhibit a DTG peak (Varhegyi et al., 1989). The TGA curve of STA also exhibited two main decomposition events, but they were better defined in comparison with SB. Compared to SB, STA showed a lower thermal stability, as indicated by the lower initial 

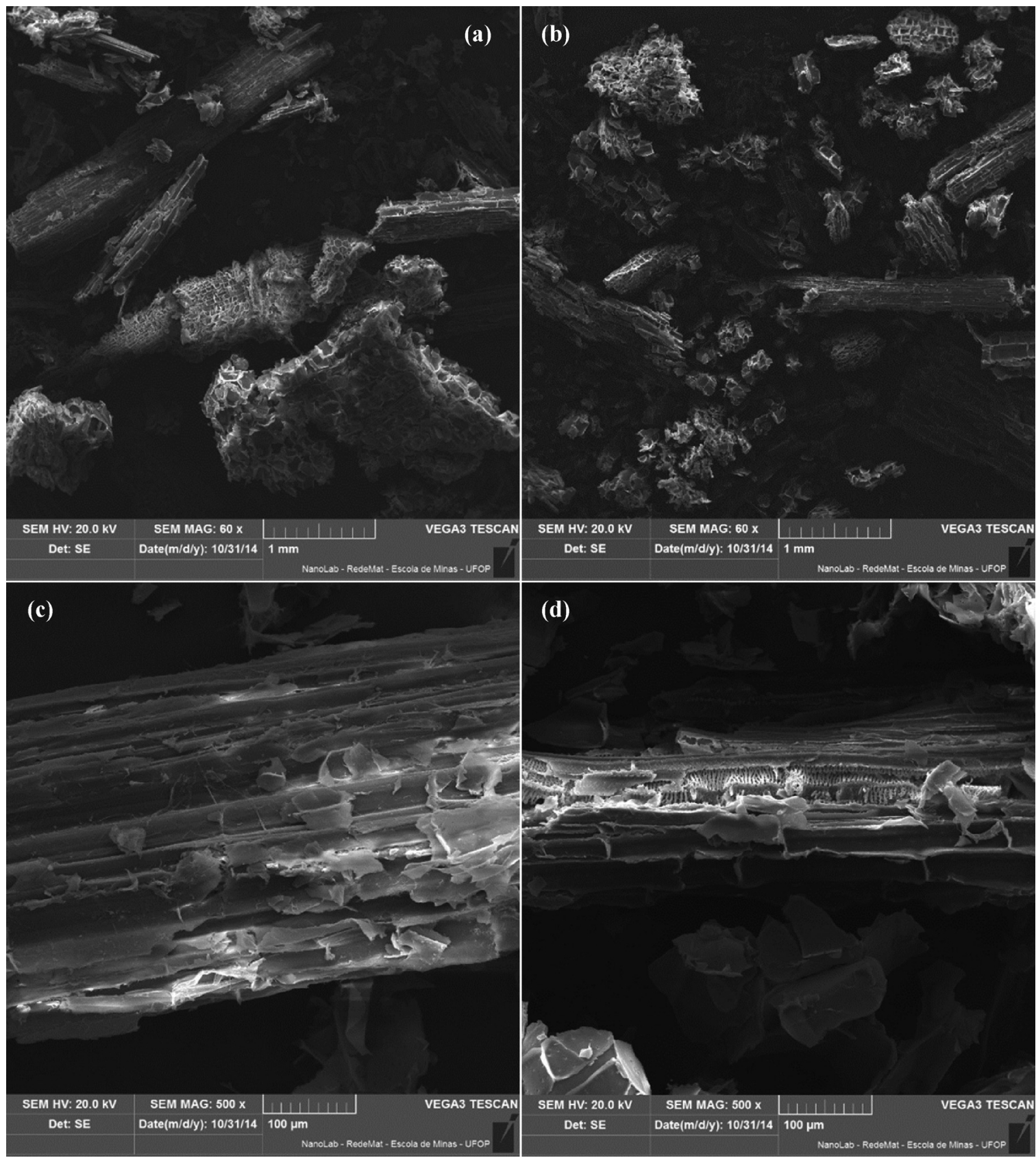

Fig. 3. SEM images of SB (a and c) and STA (b and d) at 60 and 500 fold magnification.

Table 2

TGA data for the thermal decomposition of SB and STA.

\begin{tabular}{lcc}
\hline Parameters $^{\mathrm{a}}$ & $\mathrm{SB}$ & $\mathrm{STA}$ \\
\hline$T_{i, 1}\left({ }^{\circ} \mathrm{C}\right)$ & 35.3 & 36.4 \\
$T_{m, 1}\left({ }^{\circ} \mathrm{C}\right)$ & 53.0 & 58.0 \\
$\Delta W_{1}(\%)$ & 5.45 & 4.98 \\
$T_{i, 2}\left({ }^{\circ} \mathrm{C}\right)$ & 202.3 & 134.0 \\
$T_{m, 2}\left({ }^{\circ} \mathrm{C}\right)$ & 322.0 & 242.4 \\
$\Delta W_{2}(\%)$ & 33.85 & 48.68 \\
$T_{i, 3}\left({ }^{\circ} \mathrm{C}\right)$ & 340.0 & 293.4 \\
$T_{m, 3}\left({ }^{\circ} \mathrm{C}\right)$ & 368.5 & 324.3 \\
$\Delta W_{3}(\%)$ & 44.36 & 24.11 \\
$T_{i, 4}\left({ }^{\circ} \mathrm{C}\right)$ & 404.0 & 363.8 \\
$T_{m, 4}\left({ }^{\circ} \mathrm{C}\right)$ & - & - \\
$\Delta W_{4}(\%)$ & 10.46 & 8.30 \\
\hline
\end{tabular}

${ }^{\mathrm{a}} T_{i}$ : initial decomposition temperature. $T_{\mathrm{D}}$ : maximum decomposition temperature (DTG peak), and $\Delta W$ : weight loss in the decomposition event. decomposition temperatures $\left(T_{i}\right)$. The DTG peaks at $T_{\mathrm{m}, 2}$ and $T_{\mathrm{m}, 3}$ for STA were also shifted to lower temperatures in comparison with $T_{\mathrm{m}, 2}$ and $T_{\mathrm{m}, 3}$ for SB. The second weight loss for STA also increased in relation to SB, whereas the third weight loss for STA was smaller than SB. These results demonstrate that the esterification of SB with TA decreases its thermal stability. Similar trends were observed by Nada and Hassan (2006) and Ferreira et al. (2015), who studied the succinylation ( $T_{\mathrm{m}, 2}$ and $T_{\mathrm{m}, 3}$ were 319 and $417^{\circ} \mathrm{C}$, respectively) and malonylation ( $T_{\mathrm{m}, 2}$ and $T_{\mathrm{m}, 3}$ were 206.9 and $350.5^{\circ} \mathrm{C}$, respectively) of SB.

\subsubsection{Point of zero charge (PZC)}

The PZC was used to assess the surface properties of the STA adsorbent. The $\mathrm{pH}$ necessary to give a net zero surface charge can be related to the acidity constant $\left(K_{a}\right)$ of an adsorbent material (Noh and Schwarz, 1990). Therefore, the surface of an adsorbent has a net 
positive charge at $\mathrm{pH}<\mathrm{PZC}$, whereas at $\mathrm{pH}>\mathrm{PZC}$, it has a net negative surface charge. The PZC of the STA adsorbent was found to be $3.16 \pm 0.07$. The $\mathrm{p} K_{\mathrm{a}}$ values of the trimellitic acid corresponding to position of carboxyl groups 1,2 , and 4 are 2.52, 3.84, and 5.20 (Fig. 1), respectively (Braude and Nachod, 1955). The comparison between the PZC of STA and the $\mathrm{p} K_{\mathrm{a}}$ values of trimellitic acid suggests that electronic effects provided by the presence of the ester linkage between the trimellitate and the hydroxyl groups of SB influence the acidity of the remaining carboxyl groups. The PZC value of STA suggests that the adsorption of metal ions will take place at $\mathrm{pH} \geq 3.16$.

\subsubsection{Scanning electron microscopy (SEM)}

SEM was used to assess the morphological and surface features of the SB and STA adsorbent. SEM images were also used to assess the changes in the surface of SB after chemical modification with TA. Fig. 3 shows SEM images of SB and STA at 60 ( $a$ and $b$ ) and at 500fold ( $c$ and d) magnification. As can be seen in Fig. 3a, the SB (the 60 -mesh fraction) is composed of a variety of particles of different elements with different sizes and morphologies. The morphology of the SB particles (Fig. 3a) suggests that the milling process partially disintegrated the fibers, as the presence of damaged fibrous and pith material is noticeable. As can be seen in Fig. 3b, after chemical modification of SB with TA, the particle size was apparently reduced. Disintegration of some particles may have been caused by swelling and agitation during the chemical modification. In Fig. 3c, it is noticeable that the surface of the fibers was exposed during the milling process and its open interior can be seen. After chemical modification, the fibers were more exposed and the presence of porous elements can be seen, as shown in Fig. 3d. The exposure of these pores may increase the diffusion of metal ions into the fibers, which may increase the adsorption capacity of the STA adsorbent.

\subsubsection{Energy dispersive X-ray (EDX) spectroscopy}

EDX spectroscopy was used to map the surface of the STA adsorbent in order to assess the adsorption sites containing adsorbed metal ions and their distribution along the surface of the adsorbent. Supplementary Figs. 2a-c show the distribution of $\mathrm{Co}^{2+}, \mathrm{Cu}^{2+}$, and $\mathrm{Ni}^{2+}$ on the surface of the STA adsorbent. As can be seen in Supplementary Figs. 2a-c, a heterogeneous distribution of $\mathrm{Co}^{2+}, \mathrm{Cu}^{2+}$, and $\mathrm{Ni}^{2+}$ was observed on the surface of STA adsorbent with a higher concentration of metal ions at some regions. The Langmuir and Sips models provides better fits for the adsorption of $\mathrm{Co}^{2+}, \mathrm{Cu}^{2+}$, and $\mathrm{Ni}^{2+}$ on the STA adsorbent, which suggests a homogeneous adsorption layer on the STA surface. However, in Supplementary Figs. 2a-c, it seems that there are some preferred adsorption sites. Nevertheless, the Langmuir model would be representative, considering that there is no evidence of multilayer formation, only the presence of sparsely and preferential adsorption sites. Similar results were reported by Vieira and Beppu (2006) for the adsorption of $\mathrm{Hg}^{2+}$ on raw and crosslinked chitosan films.

\subsection{Adsorption experiments}

\subsubsection{Effect of solution $\mathrm{pH}$ on metal ion adsorption}

The effect of the solution $\mathrm{pH}$ on metal ion adsorption was evaluated at $25^{\circ} \mathrm{C}$ with a $0.79 \mathrm{mmol} / \mathrm{L}$ metal ion solution, $130 \mathrm{rpm}$, $0.2 \mathrm{~g} / \mathrm{L}$ adsorbent, as well as 180,250 , and 75 min equilibrium time $\left(t_{e}\right)$ (based on kinetic data) for $\mathrm{Co}^{2+}, \mathrm{Cu}^{2+}$, and $\mathrm{Ni}^{2+}$, respectively. Fig. 4 shows the equilibrium adsorption capacity $\left(q_{e}\right)$ of $\mathrm{Co}^{2+}, \mathrm{Cu}^{2+}$, and $\mathrm{Ni}^{2+}$ on the STA adsorbent as a function of the solution $\mathrm{pH}$ from 2.0 to 5.75. The uptake of metal ions from aqueous solution hardly depends on the solution $\mathrm{pH}$, as the $\mathrm{pH}$ affects both the surface charge of the adsorbent and the form of the metallic ions in the aqueous solution (Karnitz et al., 2009; Srivastava et al., 2009). The surface charge of an adsorbent in aqueous solution is

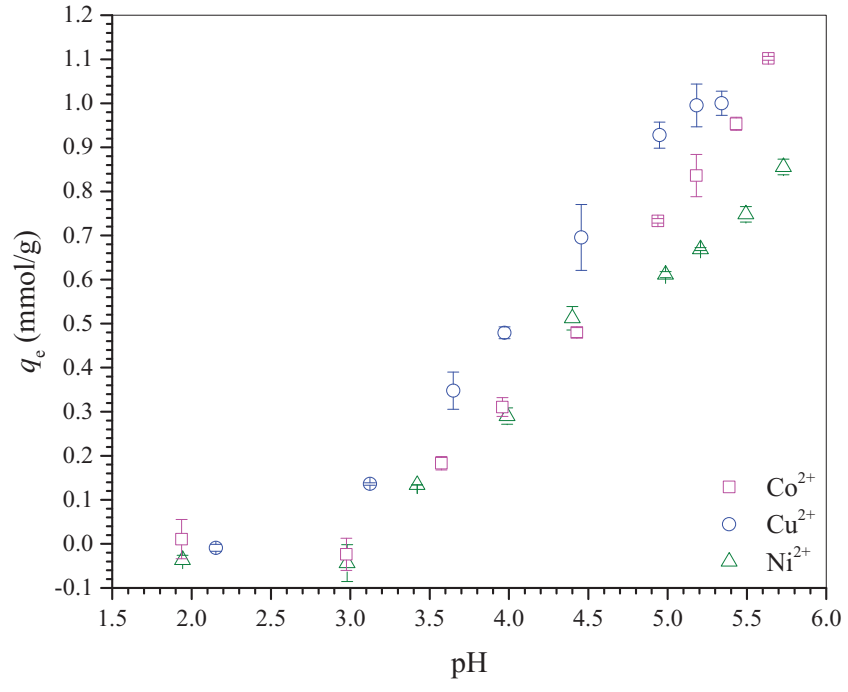

Fig. 4. Effect of $\mathrm{pH}$ on adsorption of $\mathrm{Co}^{2+}, \mathrm{Cu}^{2+}$, and $\mathrm{Ni}^{2+}$ on the STA $(0.79 \mathrm{mmol} / \mathrm{L}$ $\mathrm{M}^{2+}, 130 \mathrm{rpm}, 25^{\circ} \mathrm{C}, 0.2 \mathrm{~g} / \mathrm{L} \mathrm{STA}$ and 180,250 , and $75 \mathrm{~min}$ of shaking for $\mathrm{Co}^{2+}, \mathrm{Cu}^{2+}$, and $\mathrm{Ni}^{2+}$, respectively).

related to its PZC value. The PZC of STA was 3.16. Consequently, the adsorption of metal ions was favored at $\mathrm{pH}>\mathrm{PZC}$, where the STA surface is negatively charged, owing to deprotonation of the carboxylate groups of the trimellitate moiety that is grafted on SB. Fig. 4 shows that the $q_{e}$ increased as the solution $\mathrm{pH}$ increased, and a plateau was not reached. At low $\mathrm{pH}$ values $(\mathrm{pH}<3)$, the carboxylate groups on the STA surface were protonated and the adsorption of metal ions did not take place. From pH values slightly higher than PZC, the adsorption begins to take place as a consequence of strong attractions between the negatively charged carboxylate groups containing unshared electron pairs on the STA surface and cationic metal ions in solution. Adsorption at $\mathrm{pH}$ values higher than 5.75 was not studied, as the formation of metal-hydrolyzed species $\left[\mathrm{M}(\mathrm{OH})^{+}\right]$and the precipitation of metal ions $\left[\mathrm{M}(\mathrm{OH})_{2(\mathrm{~s})}\right]$ may occur. Thus, the pH values of 5.5 for $\mathrm{Cu}^{2+}$ and 5.75 for $\mathrm{Co}^{2+}$ and $\mathrm{Ni}^{2+}$ were considered as optimum $\mathrm{pH}$ values for the subsequent adsorption studies.

\subsubsection{Adsorption kinetics}

The adsorption kinetics represent one of the most important parameters for designing a wastewater treatment system with a batch adsorption process (Ferreira et al., 2015). Pseudo-first- and second-order kinetic models were used to model the adsorption rate of metal ions on the STA adsorbent at pH 5.5 for $\mathrm{Cu}^{2+}$ and 5.75 for $\mathrm{Co}^{2+}$ and $\mathrm{Ni}^{2+}$ at $25^{\circ} \mathrm{C}, 130 \mathrm{rpm}, 0.79 \mathrm{mmol} / \mathrm{L} \mathrm{M}^{2+}$, and $0.2 \mathrm{~g} / \mathrm{L}$ adsorbent.

The pseudo-first-order kinetic model of Lagergren (1898) defines the adsorption rate in terms of adsorption capacity as follows in Eq. (6):

$$
\frac{\mathrm{dq}_{t}}{\mathrm{dt}}=k_{1}\left(q_{e}-q_{t}\right)
$$

where $q_{e}$ and $q_{t}(\mathrm{mmol} / \mathrm{g})$ are the adsorption capacities at equilibrium $t_{e}$ and time $t(\mathrm{~min})$, respectively, and $k_{1}\left(\mathrm{~min}^{-1}\right)$ is the pseudo-first-order rate constant. Rearranging and integrating Eq. (6) using the boundary conditions $q_{t}=0$ at $t=0$ and $q_{t}=q_{t}$ at $t=t$, gives Eq. (7):

$q_{t}=q_{e}\left(1-\exp ^{-k_{1} t}\right)$

The pseudo-second-order kinetic model of Ho and McKay (1998) also defines the adsorption rate in terms of adsorption capacity; however, it assumes that the rate-limiting step may be chemical adsorption involving valency forces through sharing or exchange of 
Table 3

Results of nonlinear regression analysis of the experimental data for adsorption of metal ions on STA $\left(0.79 \mathrm{mmol} / \mathrm{L} \mathrm{M}^{2+}, 25^{\circ} \mathrm{C}, 130 \mathrm{rpm}, 0.2 \mathrm{~g} / \mathrm{L} \mathrm{STA}\right)$.

\begin{tabular}{|c|c|c|c|}
\hline Parameters & $\mathrm{Co}^{2+}$ & $\mathrm{Cu}^{2+}$ & $\mathrm{Ni}^{2+}$ \\
\hline $\mathrm{pH}$ & 5.75 & 5.5 & 5.75 \\
\hline$t_{\mathrm{e}}(\min )$ & 180 & 250 & 75 \\
\hline$q_{e, \exp }(\mathrm{mmol} / \mathrm{g})$ & $1.168 \pm 0.026$ & $0.979 \pm 0.011$ & $0.849 \pm 0.020$ \\
\hline \multicolumn{4}{|c|}{ Pseudo-first-order } \\
\hline $\begin{array}{l}q_{e, \text { est }}(\mathrm{mmol} / \mathrm{g}) \\
k_{1}\left(\mathrm{~min}^{-1}\right) \\
R^{2} \\
\chi^{2_{\text {red }}}\end{array}$ & $\begin{array}{l}1.062 \pm 0.047 \\
(7.22 \pm 1.16) \times 10^{-2} \\
0.8816 \\
0.0179\end{array}$ & $\begin{array}{l}0.808 \pm 0.047 \\
(7.87 \pm 1.69) \times 10^{-2} \\
0.7736 \\
0.0231\end{array}$ & $\begin{array}{l}0.782 \pm 0.03 \\
(1.76 \pm 0.33) \times 10^{-1} \\
0.8419 \\
0.0108\end{array}$ \\
\hline \multicolumn{4}{|c|}{ Pseudo-second-order } \\
\hline $\begin{array}{l}q_{e, \text { est }}(\mathrm{mmol} / \mathrm{g}) \\
k_{2}(\mathrm{~g} / \mathrm{mmol} \mathrm{min}) \\
R^{2} \\
\chi^{2_{\text {red }}}\end{array}$ & $\begin{array}{l}1.153 \pm 0.035 \\
(8.74 \pm 1.30) \times 10^{-2} \\
0.9580 \\
0.0064\end{array}$ & $\begin{array}{l}0.979 \pm 0.051 \\
(7.80 \pm 1.93) \times 10^{-2} \\
0.8694 \\
0.0133\end{array}$ & $\begin{array}{l}0.849 \pm 0.020 \\
(2.84 \pm 0.38) \times 10^{-1} \\
0.9617 \\
0.0026\end{array}$ \\
\hline
\end{tabular}
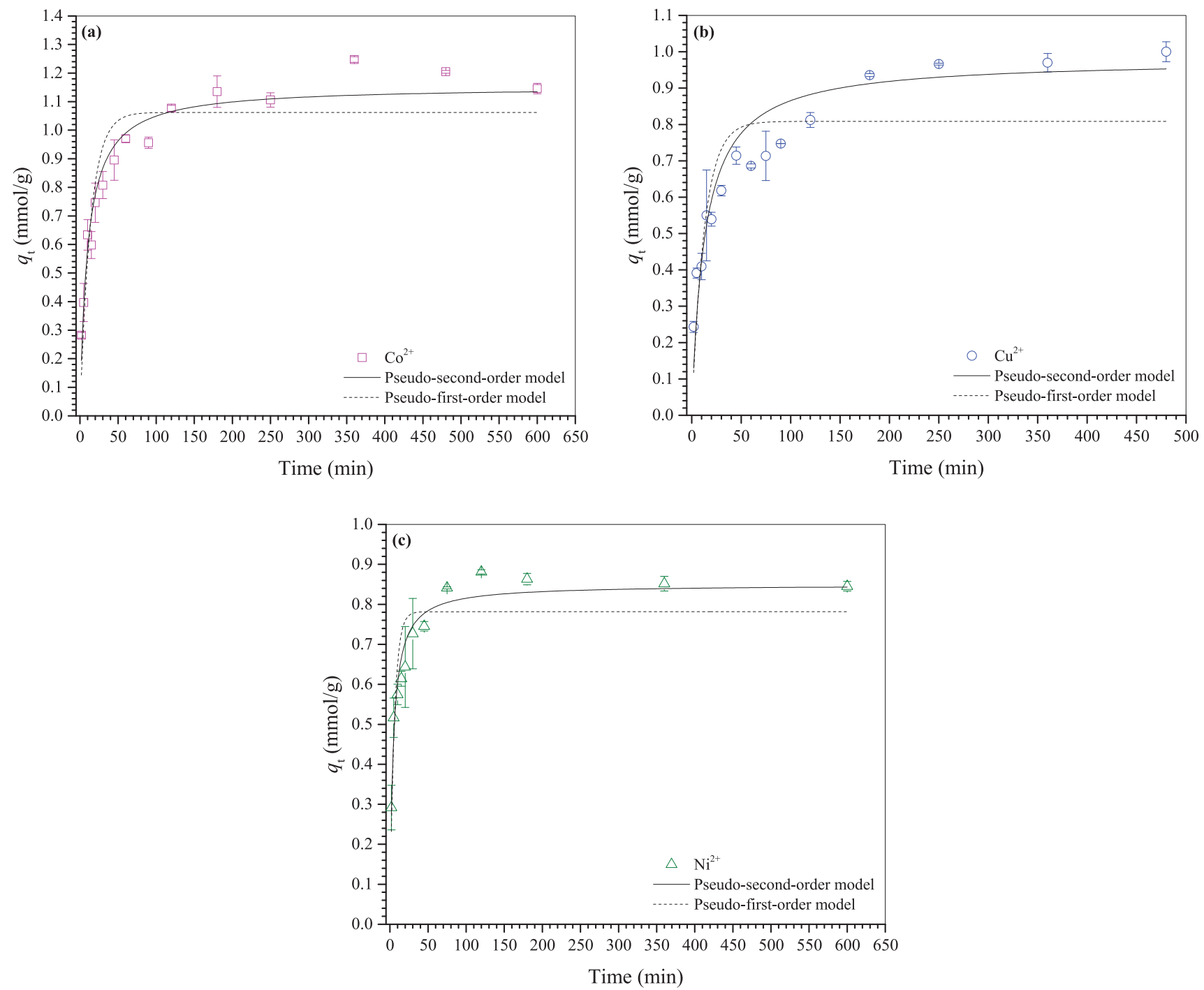

Fig. 5. Adsorption kinetics of (a) $\mathrm{Co}^{2+}$, (b) $\mathrm{Cu}^{2+}$, and (c) $\mathrm{Ni}^{2+}$ on the $\mathrm{STA}$ at $\mathrm{pH} 5.75$ for $\mathrm{Co}^{2+}$ and $\mathrm{Ni}^{2+}$ and $5.5 \mathrm{for} \mathrm{Cu}^{2+}, 0.79 \mathrm{mmol} / \mathrm{L} \mathrm{M}^{2+}, 25{ }^{\circ} \mathrm{C}, 130 \mathrm{rpm}$, and $0.2 \mathrm{~g} / \mathrm{L} \mathrm{STA}^{2}$

electrons between adsorbate and adsorbent (Ho and McKay, 1999). It can be expressed as Eq. (8):

$\frac{\mathrm{dq}_{t}}{\mathrm{dt}}=k_{2}\left(q_{e}-q_{t}\right)^{2}$

where $q_{e}$ and $q_{t}(\mathrm{mmol} / \mathrm{g})$ are the adsorption capacities at equilibrium $t_{e}$ and time $t(\mathrm{~min})$, respectively, and $k_{2}(\mathrm{~g} / \mathrm{mmol} \mathrm{min})$ is the pseudo-second-order rate constant. Rearranging and integrat- ing Eq. (8) using boundary conditions $q_{t}=0$ at $t=0$ and $q_{t}=q_{t}$ at $t=t$, gives Eq. (9):

$q_{t}=\frac{k_{2} q_{e}^{2} t}{1+k_{2} q_{e} t}$

The results were obtained by nonlinear regression analysis of pseudo-first- and second-order kinetic models using the 
Microcal OriginPro $2015^{\mathrm{TM}}$ set to use the iteration algorithm as Levenberg-Marquardt and the weight method as the statistical [Eq. (10)]. In this procedure the weights are used to minimize the $\chi^{2}$ [Eq. (11)] in order to obtain the best fit. Both the coefficient of determination $\left(R^{2}\right)$ and reduced $\chi^{2}$ [Eq. (12)] were used to measure the quality of the nonlinear regression analysis and define the best model describing the adsorption.

$w_{i}=\frac{1}{y_{i}}$

where $w_{i}$ is the weighting coefficient and $y_{i}$ is the experimental data point.

$\chi^{2}=\sum_{i=1}^{n} w_{i}\left(y_{i}-\hat{y}_{i}\right)^{2}$

where $\hat{y}_{i}$ is the theoretical data point calculated by the model.

$\chi_{\text {red }}^{2}=\frac{\chi^{2}}{v}$

where $\chi^{2}$ red is the reduced chi-square value and $v$ is the number of degrees of freedom.

Table 3 shows the results of nonlinear regression analysis of kinetic data. Plots of $q_{t}$ against $t$ are shown in Fig. 5a-c for the kinetic data and nonlinear fits for pseudo-first- and second-order kinetic models (experimental kinetic data available in Supplementary Table 1 ). As can be seen in Table 3, both values of $R^{2}$ and $\chi^{2}$ obtained from fitting the experimental data to the pseudo-second-order model were higher and lower in comparison with pseudo-firstorder model, respectively. Furthermore, when the experimental equilibrium adsorption capacity $\left(q_{\mathrm{e}, \exp }\right)$ is compared to the estimated equilibrium adsorption capacity $\left(q_{\mathrm{e}, \mathrm{est}}\right)$, it is noticeable that the values provided by the pseudo-second-order model were closer than those provided by the pseudo-first-order model, indicating that the pseudo-second-order model better describes the adsorption kinetics of $\mathrm{Co}^{2+}, \mathrm{Cu}^{2+}$, and $\mathrm{Ni}^{2+}$ on the STA. The ratios of $k_{2, \mathrm{Co} / \mathrm{Cu}}$, $k_{2, \mathrm{Ni} / \mathrm{Co}}$ and $k_{2, \mathrm{Ni} / \mathrm{Cu}}$ are $1.12,9.72$, and 10.9 , respectively. This means that $\mathrm{Ni}^{2+}$ is adsorbed by STA almost 10 times faster than $\mathrm{Co}^{2+}$ and $\mathrm{Cu}^{2+}$. This finding indicates that it would be possible to make a kinetic separation of $\mathrm{Ni}^{2+}$ with respect to $\mathrm{Co}^{2+}$ and $\mathrm{Cu}^{2+}$ in a multicomponent ion solution if a low agitation time is used. For example, the separation of $\mathrm{Co}^{2+}, \mathrm{Cu}^{2+}$, and $\mathrm{Ni}^{2+}$ from aqueous solutions is often required in hydrometallurgy processing (Pośpiech and Walkowiak, 2007) and industrial wastes (Yavuz et al., 2003).

\subsubsection{Adsorption isotherms}

Adsorption isotherms describe how various types of pollutants interact with the adsorbent materials, and, therefore, are critical in the elucidation of the adsorption mechanism, and in determining the equilibrium adsorption capacity and their influence on the surface properties on adsorption. Thus, they are crucial in the design of adsorption systems (Ferreira et al., 2015; Foo and Hameed, 2010). Adsorption of $\mathrm{Co}^{2+}, \mathrm{Cu}^{2+}$, and $\mathrm{Ni}^{2+}$ on the STA was studied in monoand bi-component aqueous solutions at $25^{\circ} \mathrm{C}, 130 \mathrm{rpm}, 0.2 \mathrm{~g} / \mathrm{L} \mathrm{STA}$, $0.05-1.12 \mathrm{mmol} / \mathrm{L} \mathrm{M}^{2+}$, and an equilibrium time of $300 \mathrm{~min}$ (based on kinetic data of Section 3.2.2).

\subsubsection{Monocomponent adsorption.}

Monocomponent isotherm equations of Langmuir, Freundlich, Sips, and Redlich-Peterson (R-P) have been used to describe the equilibrium characteristics of adsorption (Srivastava et al., 2006).

The Freundlich isotherm (Freundlich, 1906) derivation assumes adsorption on a heterogeneous surface with a non-uniform distribution of heat of adsorption over the surface. Whereas, the Langmuir isotherm (Langmuir, 1918) assumes adsorption on a homogeneous surface with the adsorption sites having the same energy or equal affinity for the adsorbate (Srivastava et al., 2006).

The Sips (Langmuir-Freundlich) isotherm (Sips, 1948) can be described as follows in Eq. (13):

$q_{e}=Q_{\max } \frac{\left(b C_{e}\right)^{1 / n}}{1+\left(b C_{e}\right)^{1 / n}}$

where $q_{e}(\mathrm{mmol} / \mathrm{g})$ is the equilibrium adsorption capacity, $C_{e}$ $(\mathrm{mmol} / \mathrm{L})$ is the metal ion equilibrium concentration in the solution, $Q_{\max }$ is the maximum adsorption capacity $(\mathrm{mmol} / \mathrm{g}), b(\mathrm{~L} / \mathrm{mmol})$ is the Sips constant related to the energy of adsorption, and $n$ is the parameter characterizing the heterogeneity of adsorption system. If parameter $n$ is unity, the Sips isotherm [Eq. (13)] reduces to the Langmuir isotherm [Eq. (16)] for ideal surfaces.

The R-P isotherm (Redlich and Peterson, 1959) can be described as follows in Eq. (14):

$q_{e}=\frac{K_{\mathrm{R}} C_{e}}{1+a_{\mathrm{R}} C_{e}^{\beta}}$

where $K_{\mathrm{R}}(\mathrm{L} / \mathrm{g})$ and $a_{\mathrm{R}}(\mathrm{L} / \mathrm{mmol})$ are the R-P isotherm constants and $\beta$ is the $\mathrm{R}-\mathrm{P}$ isotherm exponent, which is dimensionless and lies between 0 and 1 .

For high concentrations, the R-P isotherm [Eq. (14)] reduces to the Freundlich isotherm as follows in Eq. (15):

$q_{e}=K_{\mathrm{F}} C_{e}^{1 / n}$

where $K_{\mathrm{F}}=K_{\mathrm{R}} / a_{\mathrm{R}}$ is the Freundlich constant $\left[(\mathrm{mmol} / \mathrm{g})(\mathrm{L} / \mathrm{mmol})^{1 / n}\right]$ and $n$ is the heterogeneity factor $(1 / n=1-\beta)$ (Srivastava et al., 2006).

For $\beta=1$, Eq. (14) reduces to the Langmuir isotherm as follows in Eq. (16):

$q_{e}=\frac{Q_{\max } b C_{e}}{1+b C_{e}}$

where $b(\mathrm{~L} / \mathrm{mmol})$ is the Langmuir constant related to the energy of adsorption and $Q_{\max }=K_{\mathrm{R}} / a_{\mathrm{R}}$ is the maximum adsorption capacity $(\mathrm{mmol} / \mathrm{g})$.

For $\beta=0$, Eq. (14) reduces to the Henry's equation as follows in Eq. (17):

$q_{e}=\frac{K_{\mathrm{R}} C_{e}}{1+a_{\mathrm{R}}}$

The change in free energy of adsorption of the system $\left(\Delta_{\mathrm{ads}} G^{\circ}\right)$ can be calculated as follows in Eq. (18) (Liu, 2009):

$\Delta_{\mathrm{ads}} G^{\circ}=-\mathrm{RT} \ln K_{a}$

where $K_{a}$ is the thermodynamic equilibrium constant, $T$ (K) is the absolute temperature, and $R$ is the ideal gas constant $(8.314 \mathrm{~J} / \mathrm{K} \mathrm{mol})$.

The thermodynamic equilibrium constant can be calculated from Langmuir constant, $b$, as follows in Eq. (19) (Liu, 2009):

$K_{a}=\left[\frac{b}{\gamma_{e}}(1 \mathrm{~mol} / L)\right]$

where $\gamma_{e}$ is the activity coefficient in the equilibrium (dimensionless) at $25^{\circ} \mathrm{C}$.

When the adsorbate is a metal ion, the activity coefficient is strongly affected and it rapidly decreases as the ionic strength increases. For this reason, it is necessary to correct the activity coefficient for each adsorption system studied using the extended 
Debye-Hückel law [Eq. (20)] to provide a correct calculation of $\Delta_{\text {ads }} G^{\circ}$, as postulated by Liu (2009).

$\log \gamma_{e}=\frac{-0.509 z^{2} \sqrt{I_{e}}}{1+\left(\alpha \sqrt{I_{e} / 305}\right)}$

where $z$ is the charge of the ion, $I_{\mathrm{e}}(\mathrm{mol} / \mathrm{L})$ is the ionic strength in the equilibrium and $\alpha(\mathrm{pm})$ is the ion size considered as $600 \mathrm{pm}$ for $\mathrm{Co}^{2+}, \mathrm{Cu}^{2+}$, and $\mathrm{Ni}^{2+}$ (Harris, 2010). The ionic strength was calculated using the first equilibrium concentration data point of the plateau of the mono- and bi-component adsorption isotherms.

Monocomponent isotherm model parameters were found using Microcal OriginPro ${ }^{\mathrm{TM}} 2015$ software by minimizing $\chi^{2}$ as presented in Section 3.2.2.

The equilibrium monocomponent adsorption isotherms for the adsorption of $\mathrm{Co}^{2+}, \mathrm{Cu}^{2+}$, and $\mathrm{Ni}^{2+}$ on the STA at $25^{\circ} \mathrm{C}, 130 \mathrm{rpm}$, and $0.2 \mathrm{~g} / \mathrm{L}$ STA are shown in Fig. 6a-c. The monocomponent adsorption was investigated at $\mathrm{pH} 5.75$ for $\mathrm{Co}^{2+}$ and $\mathrm{Ni}^{2+}$ and 5.5 for $\mathrm{Cu}^{2+}$. Table 4 presents the results of modeling the experimental adsorption data through nonlinear regression analysis for the four monocomponent isotherms (Langmuir, Freundlich, Sips, and R-P) (experimental equilibrium data available in Supplementary Table 2 ). Table 4 shows that considering the values of $Q_{\text {max,exp }}, R^{2}$, and $\chi^{2}$ the adsorption of $\mathrm{Co}^{2+}$ was best described by the Sips isotherm, whereas the adsorption of $\mathrm{Cu}^{2+}$ and $\mathrm{Ni}^{2+}$ was best described by the Langmuir isotherm. In fact, the STA presents a heterogeneous surface where carboxylic acid groups compose the majority of the chemical functional groups. However, there are other functional groups, such as phenolic and carbonyl groups, in lignin. Thus, the surface of STA is not composed of adsorption sites with equal energy or affinity to the adsorbate. Therefore, the adsorption system cannot be considered as fully Langmuirian. In other words, although the Langmuir model failed to describe the adsorption system to a certain degree, the use of estimated Langmuir constants for comparison of the STA performance is essential. The Sips isotherm constant, $n$, can be used as an estimation of the heterogeneity of the adsorption system, as this isotherm is a combination of Langmuir and Freundlich isotherms. The values of $n$ from the Sips isotherm for the adsorption of $\mathrm{Co}^{2+}, \mathrm{Cu}^{2+}$, and $\mathrm{Ni}^{2+}$ were reasonably close to unity. This suggests that the adsorption system is more Langmuirian than Freundlichian. The maximum metal ion adsorption capacity of the STA adsorbent presented the following order $\mathrm{Ni}^{2+}>\mathrm{Cu}^{2+}>\mathrm{Co}^{2+}$. Coordination numbers $(\mathrm{CNs})$ higher than unity indicate that more than one carboxylate group is being used to adsorb a metal ion. As the monocomponent adsorption systems were best described by the Langmuir theory, it was decided that the modified Langmuir models would be used to analyze the bicomponent adsorption data, which are presented in the next Section.

The difference between physisorption and chemisorption lies in the magnitude of changes in enthalpy and free energy. For physisorption and chemisorption, the values of $\Delta_{\mathrm{ads}} G^{\circ}$ are in the range from 0 to $-20 \mathrm{~kJ} / \mathrm{mol}$ and -80 to $-200 \mathrm{~kJ} / \mathrm{mol}$, respectively (Húmpola et al., 2013). The values of $\Delta_{\mathrm{ads}} G^{\circ}$ for adsorption of $\mathrm{Co}^{2+}, \mathrm{Cu}^{2+}$, and $\mathrm{Ni}^{2+}$ on the STA are in the range from -22.8 to $-25.2 \mathrm{~kJ} / \mathrm{mol}$, which is slightly higher than physisorption and lower than chemisorption, suggesting that a mixed mechanism may be controlling the uptake of metal ions on STA. Further evidence that can be used to understand the mechanism controlling the uptake of $\mathrm{Co}^{2+}, \mathrm{Cu}^{2+}$, and $\mathrm{Ni}^{2+}$ on the STA is the shift of the carboxylate band in the FTIR spectra, which indicates the complete deprotonation of carboxylic acid groups during the adsorption process. This shift in the carboxylate band in the FTIR spectra also indicates that valence electrons from carboxylate groups are being used to complex metal ions. However, considering the magnitude of $\Delta_{\text {ads }} G^{\circ}$, it is possible to suggest that fairly weak bond was formed between the carboxy- late groups and metal ions studied. This finding will be confirmed from desorption data, which are presented in Section 3.3.

\subsubsection{Multicomponent adsorption.}

Three bicomponent adsorption systems $\mathrm{Co}^{2+}-\mathrm{Cu}^{2+}, \mathrm{Co}^{2+}-\mathrm{Ni}^{2+}$, and $\mathrm{Cu}^{2+}-\mathrm{Ni}^{2+}$ were modeled using three predictive models: (1) the non-modified competitive Langmuir model, (2) the Jain and Snoeyink (J-S) modified extended Langmuir model, and (3) $P$-factor and one correlative or semi-predictive: modified extended Langmuir model (interaction factor). The binary mixtures of metal ions were equimolar $\left(C_{i}=C_{j}\right)$ with concentrations varying from 0.05 to $1.12 \mathrm{mmol} / \mathrm{L}$.

The non-modified competitive Langmuir model (Butler and Ockrent, 1930) is an extension of the Langmuir isotherm model for a component $i$ in a system with $N$ components and it can be described as follows in Eq. (21):

$$
q_{e, i}=\frac{Q_{\max , i} b_{i} C_{e, i}}{1+\sum_{j=1}^{N} b_{j} C_{e, j}}
$$

where $Q_{\max , i}$ and $b$ are the Langmuir constants derived from monocomponent Langmuir isotherm for components $i$ and $j$.

The J-S modified extended Langmuir model (Jain and Snoeyink, 1973 ) is a bicomponent adsorption model developed to model nonideal adsorption systems. Contrary to the non-modified extended Langmuir model, the J-S model accounts for competitive adsorption. The J-S model can be described as follows in Eqs. (22) and (23):

$q_{e, i}=\frac{\left(Q_{\max , i}-Q_{\max , j}\right) b_{i} C_{e, i}}{1+b_{i} C_{e, i}}+\frac{Q_{\max , j} b_{i} C_{e, i}}{1+b_{i} C_{e, i}+b_{j} C_{e, j}}$

$q_{e, j}=\frac{Q_{\max , j} b_{j} C_{e, j}}{1+b_{i} C_{e, i}+b_{j} C_{e, j}}$

where $Q_{\max }$ and $b$ are the Langmuir constants derived from monocomponent Langmuir isotherm for components $i$ and $j$. The first term $\left(Q_{\max , i}-Q_{\max , j}\right)$ on the left-hand side of Eq. (22) refers to the amount of solute $i$ adsorbed without competition from solute $j$; whereas, the second term on the right-hand side of Eq. (22) refers to the amount of solute $i$ adsorbed in competition with solute $j$.

The $P$-factor is a correlative technique developed by McKay and Al Duri (1987). This model assumes a Langmuir isotherm and can be described as follows in Eq. (24):

$q_{e, i, \text { multi }}=\frac{1}{P_{i}}\left(\frac{K_{L, i} C_{e, i, \text { multi }}}{1+a_{L, i} C_{e, i, \text { multi }}}\right)$

where $P_{i}$ is a "lumped" capacity factor and can be defined as follows in Eq. (25):

$P_{i}=\frac{\left(K_{L, i} / a_{L, i}\right)_{\mathrm{mono}}}{\left(K_{L, i} / a_{L, i}\right)_{\text {multi }}}=\frac{Q_{\text {max }, \text { mono }}}{Q_{\max , \text { multi }}}$

where $\left(K_{L, i} / a_{L, i}\right)_{\text {mono }}$ and $\left(K_{L, i} / a_{L, i}\right)_{\text {multi }}$ are the maximum adsorption capacities for component $i$ in a monocomponent and multicomponent system, respectively.

The modified extended competitive Langmuir model is also an extension of the Langmuir isotherm model for a component $i$ in a system with $N$ components that incorporates an interaction factor, $\eta$ [Eq. (26)] (Mathews and Weber, 1980).

$$
q_{e, i}=\frac{Q_{\max , i} b_{i}\left(C_{e, i} / \eta_{i}\right)}{1+\sum_{j=1}^{N} b_{j}\left(C_{e, j} / \eta_{j}\right)}
$$



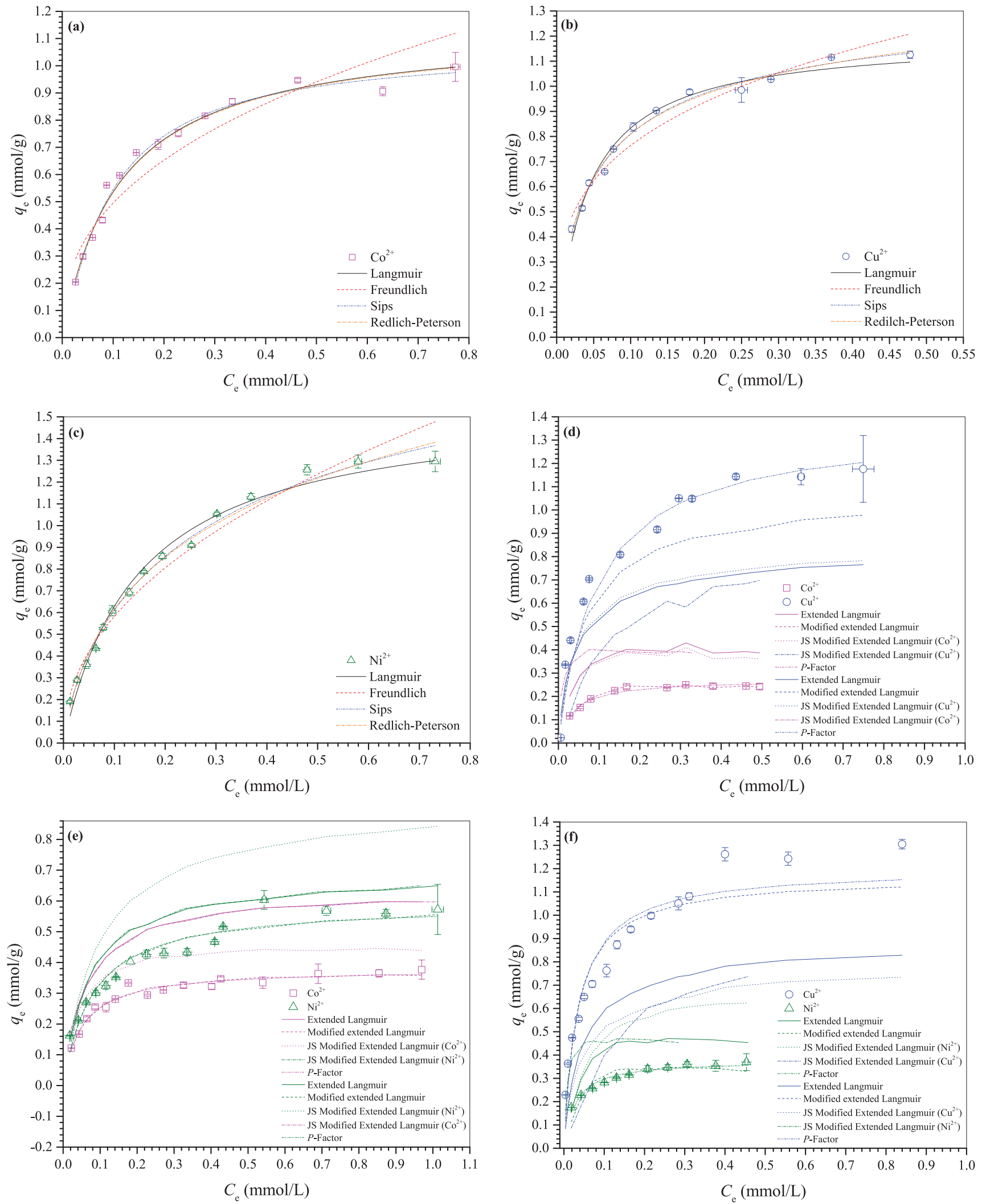

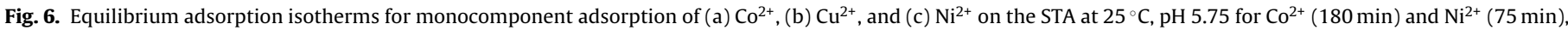
and 5.5 for $\mathrm{Cu}^{2+}(250 \mathrm{~min}), 130 \mathrm{rpm}, 0.2 \mathrm{~g} / \mathrm{L} \mathrm{STA}$ and bicomponent adsorption of (d) $\mathrm{Co}^{2+}-\mathrm{Cu}^{2+}(250 \mathrm{~min}),(\mathrm{e}) \mathrm{Co}^{2+}-\mathrm{Ni}^{2+}(180 \mathrm{~min})$, and (f) $\mathrm{Cu}^{2+}-\mathrm{Ni}^{2+}(250 \mathrm{~min})$ at $\mathrm{pH} 5.5$. 
Table 4

Results of modeling the equilibrium adsorption isotherm with monocomponent isotherm models $\left(25^{\circ} \mathrm{C}, 130 \mathrm{rpm}\right.$ and $\left.0.2 \mathrm{~g} / \mathrm{L} \mathrm{STA}\right)$.

\begin{tabular}{|c|c|c|c|c|}
\hline \multicolumn{5}{|l|}{ Monocomponent } \\
\hline \multirow[t]{7}{*}{ Isotherm model } & Parameters & $\mathrm{Co}^{2+}$ & $\mathrm{Cu}^{2+}$ & $\mathrm{Ni}^{2+}$ \\
\hline & $Q_{\max , \exp }(\mathrm{mmol} / \mathrm{g})$ & $0.950 \pm 0.026$ & $1.121 \pm 0.005$ & $1.295 \pm 0.000$ \\
\hline & $\mathrm{pH}$ & 5.75 & 5.5 & 5.75 \\
\hline & $t_{\mathrm{e}}(\min )$ & 180 & 250 & 75 \\
\hline & $\mathrm{CN}$ & 3.98 & 3.37 & 2.92 \\
\hline & $I_{\mathrm{e}}(\mathrm{mol} / \mathrm{L})$ & 0.0515 & 0.0523 & 0.0521 \\
\hline & $\gamma_{\mathrm{e}}$ & 0.886 & 0.886 & 0.886 \\
\hline \multirow[t]{5}{*}{ Langmuir } & $Q_{\text {max,est }}(\mathrm{mmol} / \mathrm{g})$ & $1.140 \pm 0.034$ & $1.197 \pm 0.028$ & $1.563 \pm 0.066$ \\
\hline & $b(\mathrm{~L} / \mathrm{mmol})$ & $8.87 \pm 0.67$ & $22.95 \pm 1.76$ & $6.73 \pm 0.65$ \\
\hline & $R^{2}$ & 0.9864 & 0.9804 & 0.9835 \\
\hline & $\chi_{\text {red }}^{2}$ & 0.0018 & 0.0015 & 0.0038 \\
\hline & $\Delta_{\text {ads }} G^{\circ}$ & $-22.83 \pm 1.72$ & $-25.19 \pm 1.93$ & $-22.15 \pm 2.14$ \\
\hline \multirow[t]{4}{*}{ Freundlich } & $K\left[\mathrm{mmol} / \mathrm{g} /(\mathrm{L} / \mathrm{mmol})^{1 / \mathrm{n}}\right]$ & $1.241 \pm 0.082$ & $1.501 \pm 0.064$ & $1.711 \pm 0.064$ \\
\hline & $n$ & $2.50 \pm 0.23$ & $3.41 \pm 0.23$ & $2.14 \pm 0.10$ \\
\hline & $R^{2}$ & 0.9083 & 0.9553 & 0.9772 \\
\hline & $\chi^{2}$ red & 0.0123 & 0.0035 & 0.0052 \\
\hline \multirow[t]{5}{*}{ Sips } & $Q_{\max , e s t}(\mathrm{mmol} / \mathrm{g})$ & $1.067 \pm 0.052$ & $1.379 \pm 0.105$ & $2.153 \pm 0.262$ \\
\hline & $b(\mathrm{~L} / \mathrm{mmol})$ & $10.36 \pm 1.17$ & $15.98 \pm 3.66$ & $2.88 \pm 0.96$ \\
\hline & $n$ & $0.89 \pm \mathrm{n} 0.08$ & $1.34 \pm 0.16$ & $1.34 \pm 0.10$ \\
\hline & $R^{2}$ & 0.9874 & 0.9884 & 0.9931 \\
\hline & $\chi^{2}$ red & 0.0017 & 0.0009 & 0.0016 \\
\hline \multirow[t]{5}{*}{ Redlich-Peterson } & $K_{\mathrm{R}}(\mathrm{L} / \mathrm{g})$ & $10.03 \pm 1.15$ & $37.81 \pm 6.41$ & $16.84 \pm 3.22$ \\
\hline & $a_{\mathrm{R}}(\mathrm{L} / \mathrm{mmol})$ & $8.82 \pm 0.95$ & $28.78 \pm 4.20$ & $10.03 \pm 1.89$ \\
\hline & $b$ & $1.00 \pm 0.07$ & $0.90 \pm 0.04$ & $0.76 \pm 0.06$ \\
\hline & $R^{2}$ & 0.9851 & 0.9869 & 0.99 \\
\hline & $\chi^{2}$ red & 0.002 & 0.001 & 0.0023 \\
\hline
\end{tabular}

where $\eta_{\mathrm{i}}$ and $\eta_{\mathrm{j}}$ are interaction factors that can be estimated from competitive adsorption data.

The predictive multicomponent adsorption isotherms were fed with monocomponent parameters obtained from nonlinear regression analysis of the Langmuir model, as presented in Table 4. The Microsoft Excel ${ }^{\mathrm{TM}} 365$ software for Windows $^{\mathrm{TM}}$ was used to calculate $R^{2}$ and $\chi^{2}$ using equilibrium concentrations for each metal ion. The interaction factor of the semi-predictive model (fed with monocomponent parameters from Langmuir model) was obtained by minimizing $\chi^{2}$ using Microcal OriginPro ${ }^{\mathrm{TM}} 2015$ software as described in Section 3.2.2. The Langmuir isotherm was also used to estimate multicomponent isotherms in order

Table 5

Results of equilibrium adsorption isotherm modeling, using multicomponent isotherm models $\left(25^{\circ} \mathrm{C}, 130 \mathrm{rpm}\right.$ and $\left.0.2 \mathrm{~g} / \mathrm{L} \mathrm{STA}\right)$.

\begin{tabular}{|c|c|c|c|c|c|c|c|}
\hline \multicolumn{8}{|l|}{ Bicomponent systems } \\
\hline Isotherm model & Parameters & $\mathrm{Co}-\mathrm{Cu}$ & $\mathrm{Cu}-\mathrm{Co}$ & $\mathrm{Co}-\mathrm{Ni}$ & $\mathrm{Ni}-\mathrm{Co}$ & $\mathrm{Cu}-\mathrm{Ni}$ & $\mathrm{Ni}-\mathrm{Cu}$ \\
\hline & $\begin{array}{l}Q_{\text {max }, \text { exp }, i}(\mathrm{mmol} / \mathrm{g}) \\
Q_{\text {max }, \text { exp }, i+j}(\mathrm{mmol} / \mathrm{g}) \\
Q_{\text {max }, \text { exp }, i, \text { multi }} / Q_{\text {max,exp,mono }} \\
\mathrm{pH} \\
t_{e, \operatorname{mono}}(\min ) \\
I_{e}(\operatorname{mol} / \mathrm{L}) \\
\gamma_{e}\end{array}$ & $\begin{array}{l}0.246 \pm 0.003 \\
1.400 \pm 0.019 \\
0.259 \\
5.5 \\
250 \\
0.0531 \\
0.886\end{array}$ & $\begin{array}{l}1.154 \pm 0.019 \\
1.030 \\
5.5 \\
250\end{array}$ & $\begin{array}{l}0.368 \pm 0.007 \\
0.944 \pm 0.021 \\
0.388 \\
5.5 \\
180 \\
0.0554 \\
0.886\end{array}$ & $\begin{array}{l}0.576 \pm 0.019 \\
0.445 \\
5.5 \\
180\end{array}$ & $\begin{array}{l}1.283 \pm 0.022 \\
1.658 \pm 0.023 \\
1.145 \\
5.5 \\
250 \\
0.0535 \\
0.886\end{array}$ & $\begin{array}{l}0.365 \pm 0.007 \\
0.282 \\
5.5 \\
250\end{array}$ \\
\hline Langmuir & $\begin{array}{l}Q_{\text {max,est }}(\mathrm{mmol} / \mathrm{g}) \\
b(\mathrm{~L} / \mathrm{mmol}) \\
R^{2} \\
\chi^{2} \text { red } \\
\Delta_{\text {ads }} G^{\circ}\end{array}$ & $\begin{array}{l}0.272 \pm 0.006 \\
27.47 \pm 2.78 \\
0.9702 \\
0.0004 \\
-32.61 \pm 3.30\end{array}$ & $\begin{array}{l}1.361 \pm 0.128 \\
10.47 \pm 2.71 \\
0.9588 \\
0.0262 \\
-30.36 \pm 2.32\end{array}$ & $\begin{array}{l}0.380 \pm 0.008 \\
20.32 \pm 1.70 \\
0.9732 \\
0.0007 \\
-24.89 \pm 2.08\end{array}$ & $\begin{array}{l}0.593 \pm 0.025 \\
12.70 \pm 1.82 \\
0.9365 \\
0.0035 \\
-23.73 \pm 3.39\end{array}$ & $\begin{array}{l}1.165 \pm 0.067 \\
30.19 \pm 6.20 \\
0.9213 \\
0.0139 \\
-25.87 \pm 5.31\end{array}$ & $\begin{array}{l}0.376 \pm 0.009 \\
38.51 \pm 4.52 \\
0.9548 \\
0.0007 \\
-26.48 \pm 3.11\end{array}$ \\
\hline $\begin{array}{l}\text { Non-modified } \\
\text { extended Langmuir }\end{array}$ & $\begin{array}{l}R^{2} \\
\chi^{2} \text { red }\end{array}$ & $\begin{array}{l}0.4237 \\
0.1128\end{array}$ & $\begin{array}{l}0.7859 \\
0.0957\end{array}$ & $\begin{array}{l}0.5822 \\
0.1173\end{array}$ & $\begin{array}{l}0.9579 \\
0.0014\end{array}$ & $\begin{array}{l}0.8766 \\
0.1006\end{array}$ & $\begin{array}{l}0.8562 \\
0.0046\end{array}$ \\
\hline $\begin{array}{l}\text { Modified extended } \\
\text { Langmuir }\end{array}$ & $\begin{array}{l}\eta_{i} \\
\eta_{j} \\
R^{2} \\
\chi_{\text {red }}^{2}\end{array}$ & $\begin{array}{l}2.178 \pm 0.089 \\
1.149 \pm 0.070 \\
0.9798 \\
0.0003\end{array}$ & $\begin{array}{l}1.571 \pm 0.517 \\
6.000 \pm 7.869 \\
0.9195 \\
0.0511\end{array}$ & $\begin{array}{l}1.378 \pm 0.099 \\
0.539 \pm 0.052 \\
0.9665 \\
0.0009\end{array}$ & $\begin{array}{l}1.366 \pm 0.161 \\
1.069 \pm 0.185 \\
0.9338 \\
0.0036\end{array}$ & $\begin{array}{l}0.735 \pm 0.151 \\
10.000 \pm 19.217 \\
0.9224 \\
0.0144\end{array}$ & $\begin{array}{l}1.440 \pm 0.192 \\
0.942 \pm 0.194 \\
0.7255 \\
0.0044\end{array}$ \\
\hline $\begin{array}{l}\text { Jain and Snoeyink (J-S) } \\
\text { modified extended } \\
\text { Langmuir }\end{array}$ & $\begin{array}{l}R^{2}{ }_{i} \\
\chi^{2} \text { red,i } \\
R^{2}{ }_{j} \\
\chi^{2}{ }_{\text {red } j}\end{array}$ & $\begin{array}{l}0.5392 \\
0.0919 \\
0.4798 \\
0.3541\end{array}$ & $\begin{array}{l}0.7988 \\
0.0900 \\
0.7125 \\
0.0986\end{array}$ & $\begin{array}{l}0.9048 \\
0.0282 \\
0.9577 \\
0.0216\end{array}$ & $\begin{array}{l}0.7581 \\
0.1008 \\
0.9793 \\
0.0123\end{array}$ & $\begin{array}{l}0.7493 \\
0.1639 \\
0.8562 \\
0.0459\end{array}$ & $\begin{array}{l}0.5281 \\
0.1418 \\
0.8856 \\
0.4262\end{array}$ \\
\hline$P$-factor & $\begin{array}{l}P_{i} \\
K_{\mathrm{L}, i} \\
a_{\mathrm{Li}}(\mathrm{L} / \mathrm{mmol}) \\
R^{2} \\
\chi^{2} \text { red }\end{array}$ & $\begin{array}{l}4.200 \\
31.32 \pm 2.64 \\
27.47 \pm 2.80 \\
0.9702 \\
0.0004\end{array}$ & $\begin{array}{l}0.879 \\
12.52 \pm 2.37 \\
10.47 \pm 2.72 \\
0.9588 \\
0.0262\end{array}$ & $\begin{array}{l}3.003 \\
23.17 \pm 1.59 \\
20.32 \pm 1.70 \\
0.9732 \\
0.0007\end{array}$ & $\begin{array}{l}2.638 \\
19.86 \pm 2.20 \\
12.70 \pm 1.83 \\
0.9365 \\
0.0035\end{array}$ & $\begin{array}{l}0.995 \\
33.15 \pm 5.38 \\
27.72 \pm 5.62 \\
0.9211 \\
0.0147\end{array}$ & $\begin{array}{l}4.163 \\
60.20 \pm 5.98 \\
38.52 \pm 4.55 \\
0.9548 \\
0.0007\end{array}$ \\
\hline
\end{tabular}


to obtain Langmuir constants $Q_{\max }$ and $b$, which are shown in Table 5.

Bicomponent adsorption occurred at $\mathrm{pH} 5.5,25^{\circ} \mathrm{C}$, and $0.2 \mathrm{~g} / \mathrm{L}$ STA. Fig. 6d-f shows the plots for binary equimolar adsorption systems $\mathrm{Co}^{2+}-\mathrm{Cu}^{2+}, \mathrm{Co}^{2+}-\mathrm{Ni}^{2+}$, and $\mathrm{Cu}^{2+}-\mathrm{Ni}^{2+}$, respectively. Table 5 shows the results of modeling the bicomponent experimental adsorption data with four multicomponent isotherm models (experimental equilibrium data available in Supplementary Table 3 ). The equilibrium adsorption data for binary metallic systems can also be discussed in terms of maximum adsorption capacity of a metal ion $i$ in the presence of another metal ion $j$, in comparison, when $i$ is present alone in the aqueous solution $\left(Q_{\text {max,exp,i,multi }} / Q_{\text {max,exp,mono }}\right)$. For $Q_{\text {max,exp,i,multi }} / Q_{\text {max,exp,mono }}>1$, the adsorption of species $i$ is promoted by the presence of the species $j$. For $Q_{\text {max,exp, }, \text {,multi }} / Q_{\text {max,exp,mono }}=1$, there is no noticeable net interaction between $i$ and $j$. For $Q_{\text {max,exp, } i \text {,multi }} / Q_{\text {max,exp,mono }}<1$, the adsorption of species $i$ is suppressed by the presence of the species $j$ (Ronda et al., 2013). As can be seen in Table 5, the adsorption of $\mathrm{Co}^{2+}$ and $\mathrm{Ni}^{2+}$ is suppressed in the presence of $\mathrm{Cu}^{2+}$, whereas the adsorption of $\mathrm{Ni}^{2+}$ is favored in the presence of $\mathrm{Co}^{2+}$. The Pearson parameter $(\delta)$ for $\mathrm{Co}^{2+}, \mathrm{Cu}^{2+}$, and $\mathrm{Ni}^{2+}$ is $0.130,0.104$, and 0.126 , respectively. These cations are considered as borderline Lewis acids, whereas a carboxylate ligand, such as an acetate ion, is considered as a hard Lewis base. However, the two carboxylate groups from a trimellitate moiety grafted onto STA behave as very weakly basic, negatively charged, oxygen-donor groups that are stabilized by resonance. Thus, based on the experimental multicomponent data, it is possible to conclude that these carboxylate groups have a higher affinity for $\mathrm{Cu}^{2+}$ than $\mathrm{Ni}^{2+}$ and $\mathrm{Co}^{2+}$. The obtained results are in good agreement with the softness order of metal ions studied $\left(\mathrm{Cu}^{2+}>\mathrm{Ni}^{2+}>\mathrm{Co}^{2+}\right)$. These results are also in good agreement with the Langmuir constants $\left(b_{\mathrm{Cu}^{2+}}>b_{\mathrm{Co}^{2+}}{ }^{2+} b_{\mathrm{Ni}^{2+}}\right)$, considering the slight difference in the Pearson parameter for $\mathrm{Co}^{2+}$ and $\mathrm{Ni}^{2+}$ (Table 4). These data also suggest that there is the possibility to separate $\mathrm{Ni}^{2+}$ from $\mathrm{Co}^{2+}$ and $\mathrm{Ni}^{2+}$ from $\mathrm{Cu}^{2+}$ using kinetic and thermodynamic control on the basis of kinetic $\left(k_{2, i} / k_{2, j}\right)$ and isotherm data $\left(Q_{\text {max,exp, } i, \text { multi }} / Q_{\text {max,exp,mono }}\right)$ using a fixed-bed adsorption column system, controlling the inlet flow rate and concentration of each metal ion. This finding can be very useful for treating effluents from acid mine drainage, industrial wastewaters, and in the pre-concentration steps of hydrometallurgical processes. The adsorption of single, binary, and ternary systems of $\mathrm{Co}^{2+}, \mathrm{Cu}^{2+}$, and $\mathrm{Ni}^{2+}$ in aqueous solutions using a fixed-bed column is the focus of subsequent parts of this paper.

Factors affecting the preference of STA for a specific metal ion may be related to the characteristics of the adsorption sites, that is, the functional groups present in its surface and the properties of the metal ions in solution (e.g., concentration, ionic size, primary and secondary valence, and coordination number) as well as the solution characteristics (e.g., pH, ionic strength, and presence of different counter ions) (Srivastava et al., 2006).

The values of $\Delta_{\mathrm{ads}} G^{\circ}$ for a multicomponent system were slightly more negative than the $\Delta_{\text {ads }} G^{\circ}$ value of a monocomponent system. The values of $\Delta_{\text {ads }} G^{\circ}$ indicate that adsorption was more favorable in multicomponent systems compared to the monocomponent systems. Considering the values of $\Delta_{\mathrm{ads}} G^{\circ}$, there is no clear experimental evidence for a change in the adsorption mechanism controlling the uptake of metal ions in the binary system in relation to single system. However, in Fig. 6e, it is noticeable that a double layer seems to have been formed, which was indicated by the formation of a second plateau in the isotherm of the Co-Ni binary system. It favored the adsorption of $\mathrm{Ni}^{2+}$ rather than $\mathrm{Co}^{2+}$. In binary systems $\mathrm{Co}-\mathrm{Cu}$ and $\mathrm{Cu}-\mathrm{Ni}$, this behavior was not observed.

As can be seen in Table 5, comparing the three binary adsorption systems, higher $R^{2}$ and lower $\chi^{2}$ values were obtained by fitting the modified extended Langmuir and $P$-factor models to the experimental adsorption data. Non-modified extended Langmuir and J-S modified extended Langmuir models exhibited a poor fit to the experimental data. These results also confirm that there are interactions between the two metal ions in the three binary adsorption systems. Supplementary Fig. 3 shows the plots of $q_{e, \text { est }}$ against $q_{e, \text { exp }}$ for the three binary adsorption systems and four competitive adsorption models tested. Supplementary Table 4 shows the slope and the intercept from plots of estimated $\left(q_{e, \text { est }}\right)$ against experimental maximum adsorption capacities $\left(q_{e, \exp }\right)$ for all competitive adsorption models tested. Supplementary Fig. 3a-f shows plots of $q_{e, \text { est }}$ versus $q_{e, \text { exp }}$ for the three bicomponent systems studied. In these graphs, most of the data points are distributed around the $45^{\circ}$ dashed line, with $95 \%$ of confidence interval, for modified extended Langmuir and $P$-factor models. For these models, the slopes and intercepts were closer to unity and zero, respectively, which indicates that these multicomponent models could estimate $q_{e, \text { est }}$ from the experimental data very well.

The maximum metal ion adsorption capacities in the binary systems $\left(Q_{\max , \exp , i+j}\right)$ (Table 5$)$ were lower than the sum of the single maximum adsorption capacities for each metal ion. Similar results were observed by Srivastava et al. (2006) for the adsorption of $\mathrm{Cd}^{2+}$ and $\mathrm{Zn}^{2+}$ on bagasse fly ash in mono- and bi-component systems. According to Srivastava et al. (2006), this result may imply that there is a variety of adsorption binding sites on the adsorbent surface exhibiting partially specific affinity to the single metal ions. These conclusions seems to violate the assumptions of the Langmuir isotherm theory, that is, the adsorbent surface is homogeneous, there is no preferential adsorption and lateral interaction between adsorbates, and the affinity of each adsorption site by the adsorbate is uniform. Although the Langmuir isotherm theory fails, to a certain degree, to fully describe the adsorption behavior of binary systems, the use of a modified extended Langmuir model seemed reasonable, as the interaction factor took into account the deviations from the non-modified extended Langmuir model and its assumptions. According to Choy et al. (2000), the P-factor model cannot account for all competitions and interactions that may influence the competitive adsorption, resulting in some deviations between $q_{e \text {,est }}$ and $q_{e, \exp }$. However, according to analysis by Choy et al. (2000), the $P$-factor model provides a major enhancement over the data estimated by the extended Langmuir model. The obtained results in this study are in good agreement with the analysis of Choy et al. (2000), as the estimation of $q_{e}$ values provided by $P$-factor was better than the extended Langmuir model.

\subsection{Desorption and reuse of the spent adsorbent}

The desorption of STA-loaded with $\mathrm{Co}^{2+}, \mathrm{Cu}^{2+}$, and $\mathrm{Ni}^{2+}$ was performed using a batch process at $25^{\circ} \mathrm{C}$ and $130 \mathrm{rpm}$ with $20.0 \mathrm{~mL}$ of $1.0 \mathrm{~mol} / \mathrm{L} \mathrm{HNO}_{3}$ for $5 \mathrm{~min}$. The desorption percentage, $E_{\mathrm{des}}$, was $100 \%$ for all metal ions studied. The suggested mechanism for the desorption of metal ions from STA-loaded with $\mathrm{Co}^{2+}$, $\mathrm{Cu}^{2+}$, and $\mathrm{Ni}^{2+}$ is that of ion exchange, in which metal ions are exchange by hydronium ions. Desorption tests with $0.05 \mathrm{~mol} / \mathrm{L}$ $\mathrm{ClCH}_{2} \mathrm{COOH} / \mathrm{ClCH}_{2} \mathrm{COONa}$ buffer $(\mathrm{pH} 2)$ were also performed. These tests revealed that the monochloroacetate/monochloroacetic acid buffer was efficient in desorbing the metal ions from STA. The desorption efficiency attained was about $50 \%$. The reason for the desorption efficiency of the buffer solution being lower than nitric acid solution was the change in the $\mathrm{pH}$ of the buffer solution to higher values $(\mathrm{pH}>2)$ during the desorption process. This result proves that ion exchange is the mechanism controlling the desorption process.

FTIR spectra of STA (blank) and STA after desorption of $\mathrm{Co}^{2+}$, $\mathrm{Cu}^{2+}$, and $\mathrm{Ni}^{2+}$ were also recorded (Supplementary Fig. 4). The same bands attributed to the success of chemical modification of SB with TA were confirmed in the adsorbents after desorption, which 
Table 6

Comparison of $Q_{\max }$ for removal of $\mathrm{Co}^{2+}, \mathrm{Cu}^{2+}$, and $\mathrm{Ni}^{2+}$ by various adsorbents.

\begin{tabular}{lllll}
\hline \multirow{2}{*}{ Adsorbent } & \multicolumn{2}{l}{$Q_{\max }(\mathrm{mmol} / \mathrm{g})^{\mathrm{a}}$} & \multirow{2}{*}{ Reference } \\
\cline { 2 - 4 } & $\mathrm{Co}^{2+}$ & $\mathrm{Cu}^{2+}$ & $\mathrm{Ni}^{2+}$ & \\
\hline PET-g-(MAA/AAm) & 0.461 & 0.492 & 0.741 & Coşkun et al. (2006) \\
Sp-HPBA & 0.039 & 0.043 & 0.036 & Çimen et al. (2013) \\
Palygorskite (Brazil) & 1.604 & 1.279 & 0.078 & Oliveira et al. (2013) \\
BANPA & 0.56 & 0.49 & 0.55 & Rodrigues et al. (2013) \\
BANMA & 0.27 & 0.29 & 0.47 & Rodrigues et al. (2013) \\
PAMMAm & 0.122 & 0.201 & 0.104 & Kushwaha et al. (2013) \\
Sil-NSuc & 1.85 & 1.04 & 1.89 & Arakaki et al. (2013) \\
Celam biopolymer & 0.097 & 0.102 & 0.077 & Silva Filho et al. (2013) \\
STA & 1.140 & 1.197 & 1.563 & This study \\
\hline
\end{tabular}

a Maximum adsorption capacities obtained from the Langmuir model at $25^{\circ} \mathrm{C}$.

proves that there was no ester bond hydrolysis during desorption experiments. Furthermore, the study of re-adsorption of $\mathrm{CO}^{2+}, \mathrm{Cu}^{2+}$, and $\mathrm{Ni}^{2+}$ using the spent STA adsorbent demonstrated that the readsorption efficiency was $100 \%$ for all metal ions studied. These results prove that the STA adsorbent can be recovered and reused without loss in its adsorption capacity. The results of the studies of desorption and re-adsorption demonstrates that it is possible to recover both the metal ions and the STA adsorbent, which improves the economic feasibility of the proposed adsorption process.

\subsection{Comparison with previously reported data for $\mathrm{Co}^{2+}, \mathrm{Cu}^{2+}$, and $\mathrm{Ni}^{2+}$ adsorption}

Table 6 shows various adsorbents that have been used to remove $\mathrm{Co}^{2+}, \mathrm{Cu}^{2+}$, and $\mathrm{Ni}^{2+}$ from aqueous solutions, as reported in previous studies, for comparison purposes. Comparing the STA adsorbent with some previously reported adsorbents used for the removal of $\mathrm{Co}^{2+}, \mathrm{Cu}^{2+}$, and $\mathrm{Ni}^{2+}$, it is possible to conclude that the STA adsorbent is one of the most powerful adsorbents synthesized for this purpose.

\section{Conclusions}

Sugarcane bagasse modified with trimellitic anhydride (STA) was successfully synthesized and characterized by FTIR, elemental analysis, TGA, and PZC measurements. The percent weight gain and number of carboxylic acid groups were found to be $73.9 \%$ and $3.78 \mathrm{mmol} / \mathrm{g}$, respectively. The STA adsorbent was efficient in removing $\mathrm{Co}^{2+}, \mathrm{Cu}^{2+}$, and $\mathrm{Ni}^{2+}$ from single and binary component aqueous solutions. The adsorption kinetics followed the pseudosecond-order model. The experimental data fitted very well to the Langmuir and Sips isotherm models. The equilibrium time obtained from the kinetic study and the monocomponent maximum adsorption capacity determined by Langmuir model for adsorption of $\mathrm{Co}^{2+}$, $\mathrm{Cu}^{2+}$, and $\mathrm{Ni}^{2+}$ were 180,250 , and $75 \mathrm{~min}$ and $1.140,1.197$, and $1.563 \mathrm{mmol} / \mathrm{g}$, respectively. The bicomponent adsorption studies demonstrated that the adsorption of $\mathrm{Co}^{2+}$ and $\mathrm{Ni}^{2+}$ is suppressed in the presence of $\mathrm{Cu}^{2+}$, and $\mathrm{Ni}^{2+}$ suppresses the adsorption of $\mathrm{Co}^{2+}$. The bicomponent data fitted very well to the modified extended Langmuir and $P$-factor models. Desorption studies demonstrated that the STA adsorbent can be $100 \%$ desorbed and reused.

\section{Acknowledgements}

The authors are grateful to Universidade Federal de Ouro Preto (UFOP) (for an undergraduate PIP scholarship awarded to F.J. Gonçalves) and Fundação de Amparo à Pesquisa do Estado de Minas Gerais (FAPEMIG) (for an undergraduate PROBIC scholarship awarded to M.M.C. Elias) for funding this research (FAPEMIG grant number CEX APQ-00149/12). The authors are also grateful to Coordenação de Aperfeiçoamento de Pessoal de Nível Supe- rior (CAPES) (for an M.S. scholarship awarded to S.N.C. Ramos) and Conselho Nacional de Desenvolvimento Científico (CNPq) (for an M.S. scholarship awarded to F.S. Teodoro) and Laboratório de microscopia eletrônica, microanálises e caracterização de materiais (NanoLab/FINEP) - RedeMat Escola de Minas, UFOP and B.S. Ney, P. Sampaio for SEM-EDX analyses.

\section{Appendix A. Supplementary data}

Supplementary data associated with this article can be found, in the online version, at http://dx.doi.org/10.1016/j.indcrop.2015.05. 022

\section{References}

Ahmad, P., Prasad, N.V., 2011. Environmental Adaptations and Stress Tolerance of Plants in the Era of Climate Change. Springer, New York.

Amin, N.-U., Hussain, A., Alamzeb, S., Begum, S., 2013. Accumulation of heavy metals in edible parts of vegetables irrigated with waste water and their daily intake to adults and children, district Mardan, Pakistan. Food Chem. 136, 1515-1523.

Arakaki, L.N.H., Filha, V.L.S.A., Germano, A.F.S., Santos, S.S.G., Fonseca, M.G., Sousa, K.S., Espínola, J.G.P., Arakaki, T., 2013. Silica gel modified with ethylenediamine and succinic acid-adsorption and calorimetry of cations in aqueous solution. Thermochim. Acta 556, 34-40.

ATSDR, 2014. Support Document to the 2013 Priority List of Hazardous Substances that will be the Subject of Toxicological Profiles. Division of Toxicology and Environmental Medicine, Atlanta, GA, pp. 1-12 (accessed 21.11.14.) http:// www.atsdr.cdc.gov/SPL/resources/ATSDR_2013_SPL_Support_Document.pdf

Barakat, M.A., 2011. New trends in removing heavy metals from industrial wastewater. Arabian J. Chem. 4, 361-377.

Bhatnagar, A., Sillanpää, M., 2010. Utilization of agro-industrial and municipal waste materials as potential adsorbents for water treatment - a review. Chem. Eng. J. 157, 277-296.

Braude, E.A., Nachod, F.C., 1955. Determination of Organic Structures by Physical Methods. Academic Press Inc., New York, USA

Butler, J.A.V., Ockrent, C., 1930. Studies in electrocapillarity. Part III: the surface tensions of solutions containing two surface-active solutes. J. Phys. Chem. 34 2841-2859.

Choy, K.K.H., Porter, J.F., McKay, G., 2000. Langmuir isotherm models applied to the multicomponent sorption of acid dyes from effluent onto activated carbon. J. Chem. Eng. Data 45, 575-584.

Cimen, A., Bilgiç, A., Kursunlu, A.N., Gübbük, İ.H., Uçan, H.İ., 2013. Adsorptive removal of $\mathrm{Co}(\mathrm{II}) \mathrm{Ni}(\mathrm{II})$, and $\mathrm{Cu}(\mathrm{II})$ ions from aqueous media using chemically modified sporopollenin of Lycopodium clavatum as novel biosorbent. Desalin. Water Treat. 52, 4837-4847.

Coşkun, R., Soykan, C., Saçak, M., 2006. Adsorption of copper(II), nickel(II) and cobalt(II) ions from aqueous solution by methacrylic acid/acrylamide monomer mixture grafted poly(ethylene terephthalate) fiber. Sep. Purif. Technol. 49, 107-114.

Ferreira, B.C.S., Teodoro, F.S., Mageste, A.B., Gil, L.F., de Freitas, R.P., Gurgel, L.V.A. 2015. Application of a new carboxylate-functionalized sugarcane bagasse for adsorptive removal of crystal violet from aqueous solution: kinetic, equilibrium and thermodynamic studies. Ind. Crops Prod. 65C, 521-534.

Foo, K.Y., Hameed, B.H., 2010. Insights into the modeling of adsorption isotherm systems. Chem. Eng. J. 156, 2-10.

Freundlich, H.M.F., 1906. Over the adsorption in solution. Z. Phys. Chem. Stoch Ve $57,385-470$.

Fu, F., Wang, Q., 2011. Removal of heavy metal ions from wastewaters: a review. J. Environ. Manage. 92, 407-418.

Harris, D.C., 2010. Quantitative Chemical Analysis, 8th ed. W.H. Freeman, New York.

Haynes, W.M., 2014. CRC Handbook of Chemistry and Physics, 95th ed. Taylor \& Francis.

Ho, Y.S., McKay, G., 1998. Kinetic models for the sorption of dye from aqueous solution by wood. Process Saf. Environ. Prot. 76, 183-191.

Ho, Y.S., McKay, G., 1999. Pseudo-second order model for sorption processes. Process Biochem. 34, 451-465.

Húmpola, P.D., Odetti, H.S., Fertitta, A.E., Vicente, J.L., 2013. Thermodynamic analysis of adsorption models of phenol in liquid phase on different activated carbons. J. Chil. Chem. Soc. 58, 1541-1544.

Jain, J.S., Snoeyink, V.L., 1973. Adsorption from bisolute systems on active carbon. J. Water Pollut. Control Fed. 45, 2463-2479.

Karnitz, O., Gurgel, L.V.A., de Freitas, R.P., Gil, L.F., 2009. Adsorption of Cu(II) Cd(II), and $\mathrm{Pb}(\mathrm{II})$ from aqueous single metal solutions by mercerized cellulose and mercerized sugarcane bagasse chemically modified with EDTA dianhydride (EDTAD). Carbohydr. Polym. 77, 643-650.

Kazemipour, M., Ansari, M., Tajrobehkar, S., Majdzadeh, M., Kermani, H.R., 2008. Removal of lead, cadmium, zinc, and copper from industrial wastewater by carbon developed from walnut, hazelnut, almond, pistachio shell, and apricot stone. J. Hazard. Mater. 150, 322-327. 
Klaassen, C., 2008. Casarett \& Doull's Toxicology: The Basic Science of Poisons: The Basic Science of Poisons, 7th ed. McGraw-Hill, New York.

Kumar, U., 2006. Agricultural products and by-products as a low cost adsorbent for heavy metal removal from water and wastewater: a review. Sci. Res. Essays 1, 33-37.

Kushwaha, A.K., Gupta, N., Chattopadhyaya, M.C., 2013. Dynamics of adsorption of $\mathrm{Ni}(\mathrm{II}) \mathrm{Co}(\mathrm{II})$ and $\mathrm{Cu}(\mathrm{II})$ from aqueous solution onto newly synthesized poly[N-(4-[4-(aminophenyl) methylphenylmethacrylamide])]. Arabian J. Chem. http://dx.doi.org/10.1016/j.arabjc.2013.1006.1007

Lagergren, S.Y., 1898. Zur Theorie der sogenannten Adsorption gelöster Stoffe, Kungliga Svenska Vetenskapsakademiens, 24. Handlingar, pp. 1-39.

Langmuir, I., 1918. The adsorption of gases on plane surfaces of glass, mica and platinum. J. Am. Chem. Soc. 40, 1361-1403.

Liu, Y., 2009. Is the free energy change of adsorption correctly calculated? J. Chem. Eng. Data 54, 1981-1985.

Łyszczek, R., 2007. Thermal and spectroscopic investigations of new lanthanide complexes with 1,2,4-benzenetricarboxylic acid. J. Therm. Anal. Calorim. 90 533-539.

Mathews, A.P., Weber, W.J., 1980. Mathematical modeling of adsorption in multicomponent systems, adsorption and ion exchange with synthetic zeolites. Am. Chem. Soc. 135, 27-53.

McKay, G., Al Duri, B., 1987. Simplified model for the equilibrium adsorption of dyes from mixtures using activated carbon. Chem. Eng. Process. Process Intensif. 22, 145-156.

Miretzky, P., Cirelli, A.F., 2010. Cr(VI) and Cr(III) removal from aqueous solution by raw and modified lignocellulosic materials: a review. J. Hazard. Mater. 180, $1-19$.

Nada, A.-A.M.A., Hassan, M.L., 2006. Ion exchange properties of carboxylated bagasse. J. Appl. Polym. Sci. 102, 1399-1404.

Noh, J.S., Schwarz, J.A., 1990. Effect of $\mathrm{HNO}_{3}$ treatment on the surface-acidity of activated carbons. Carbon 28, 675-682.

Oliveira, A.B.M., Coelho, L.O., Gomes, S.S., Costa, I., Fonseca, M., de Sousa, K. Espínola, J.P., da Silva Filho, E., 2013. Brazilian palygorskite as adsorbent for metal ions from aqueous solution - kinetic and equilibrium studies. Water Air Soil Pollut. 224, 1-13.

Pavia, D., Lampman, G., Kriz, G., Vyvyan, J., 2009. Introduction to Spectroscopy, 4th ed. Cengage Learning, Belmont, USA.

Pośpiech, B., Walkowiak, W., 2007. Separation of copper(II), cobalt(II) and nickel(II) from chloride solutions by polymer inclusion membranes. Sep. Purif. Technol. 57, 461-465

Redlich, O., Peterson, D.L., 1959. A useful adsorption isotherm. J. Phys. Chem. 63 1024.
Rocha, G.J.D.M., Nascimento, V.M., Gonçalves, A.R., Silva, V.F.N., Martín, C., 2015 Influence of mixed sugarcane bagasse samples evaluated by elemental and physical-chemical composition. Ind. Crops Prod. 64, 52-58.

Rodrigues, N.F.M., Santana, S.A.A., Bezerra, C.W.B., Silva, H.A.S., Melo, J.C.P., Vieira, A.P., Airoldi, C., Silva Filho, E.C., 2013. New chemical organic anhydride immobilization process used on banana pseudostems: a biopolymer for cation removal. Ind. Eng. Chem. Res. 52, 11007-11015.

Ronda, A., Martín-Lara, M.A., Dionisio, E., Blázquez, G., Calero, M., 2013. Effect of lead in biosorption of copper by almond shell. J. Taiwan Inst. Chem. Eng. 44, 466-473.

Saikia, C.N., Dutta, N.N., Borah, M., 1993. Thermal behaviour of some homogeneously esterified products of high $\alpha$-cellulose pulps of fast growing plant species. Thermochim. Acta 219, 191-203.

Silva Filho, E.C., Santos Júnior, L.S., Silva, M.M.F., Fonseca, M.G., Santana, S.A.A. Airoldi, C., 2013. Surface cellulose modification with 2-aminomethylpyridine for copper cobalt, nickel and zinc removal from aqueous solution. Mater. Res. $16,79-84$.

Sips, R., 1948. On the structure of a catalyst surface. J. Chem. Phys. 16, 490-495.

Soetan, K., Olaiya, C., Oyewole, O., 2010. The importance of mineral elements for humans, domestic animals and plants: a review. Afr. J. Food Sci. 4, 200-222.

Srivastava, V.C., Mall, I.D., Mishra, I.M., 2006. Modelling individual and competitive adsorption of cadmium(II) and zinc(II) metal ions from aqueous solution onto bagasse fly ash. Sep. Sci. Technol. 41, 2685-2710.

Srivastava, V.C., Mall, I.D., Mishra, I.M., 2009. Competitive adsorption of cadmium(II) and nickel(II) metal ions from aqueous solution onto rice husk ash. Chem. Eng. Process. Process Intensif. 48, 370-379.

Sun, R.C., 2010. Cereal Straw as a Resource for Sustainable Biomaterials and Biofuels: Chemistry, Extractives, Lignins, Hemicelluloses and Cellulose, 1st ed. Elsevier, Oxford, UK

Varhegyi, G., Antal, M.J., Szekely, T., Szabo, P., 1989. Kinetics of the thermal decomposition of cellulose, hemicellulose, and sugarcane bagasse. Energ Fuel 3, 329-335.

Vieira, R.S., Beppu, M.M., 2006. Interaction of natural and crosslinked chitosan membranes with $\mathrm{Hg}(\mathrm{II})$ ions. Colloids Surf. A 279, 196-207.

Wan Ngah, W.S., Hanafiah, M.A.K.M., 2008. Removal of heavy metal ions from wastewater by chemically modified plant wastes as adsorbents: a review. Bioresour. Technol. 99, 3935-3948.

Yavuz, Ö., Altunkaynak, Y., Güzel, F., 2003. Removal of copper, nickel, cobalt and manganese from aqueous solution by kaolinite. Water Res. 37, 948-952. 